\title{
Effects of silica-based nanostructures with raspberry-like morphology and surfactant on the interfacial behavior of light, medium, and heavy crude oils at oil-aqueous interfaces
}

\author{
Lingyun Bai ${ }^{1}$ Chunyan $\mathrm{Li}^{1}$ - Caroline Korte ${ }^{1} \cdot$ Britta M. J. Huibers $^{1}$ • \\ Ashley R. Pales ${ }^{1} \cdot$ Wei-zhen Liang ${ }^{1} \cdot$ David Ladner $^{1} \cdot$ Hugh Daigle $^{2}$. \\ Christophe J. G. Darnault ${ }^{1}$
}

Received: 17 August 2017/ Accepted: 6 November 2017/Published online: 18 November 2017

(c) The Author(s) 2017. This article is an open access publication

\begin{abstract}
Any efficient exploitation of new petroleum reservoirs necessitates developing methods to mobilize the crude oils from such reservoirs. Here silicon dioxide nanoparticles $\left(\mathrm{SiO}_{2} \mathrm{NPs}\right)$ were used to improve the efficiency of the chemical-enhanced oil recovery process that uses surfactant flooding. Specifically, $\mathrm{SiO}_{2}$ NPs (i.e., 0, $0.001,0.005,0.01,0.05$, and $0.1 \mathrm{wt} \%)$ and Tween ${ }^{\circledR} 20$, a nonionic surfactant, at $0,0.5$, and 2 critical micelle concentration (CMC) were varied to determine their effect on the stability of nanofluids and the interfacial tension (IFT) at the oil-aqueous interface for $5 \mathrm{wt} \%$ brine-surfactant$\mathrm{SiO}_{2}$ nanofluid-oil systems for West Texas Intermediate light crude oil, Prudhoe Bay medium crude oil, and Lloydminster heavy crude oil. Our study demonstrates that $\mathrm{SiO}_{2}$ NPs may either decrease, increase the IFT of the brinesurfactant-oil systems, or exhibit no effects at all. For the brine-surfactant-oil systems, the constituents of the oil and aqueous substances affected the IFT behavior, with the nanoparticles causing a contrast in IFT trends according to the type of crude oil. For the light oil system ( 0.5 and 2 CMC Tween ${ }^{\circledR} 20$ ), the IFT increased as a function of $\mathrm{SiO}_{2}$ NP concentration, while a threshold concentration of $\mathrm{SiO}_{2}$ NPs was observed for the medium (0.5 and $2 \mathrm{CMC}$
\end{abstract}

Christophe J. G. Darnault

cdarnau@clemson.edu

1 Department of Environmental Engineering and Earth Sciences, Laboratory of Hydrogeoscience and Biological Engineering, L.G. Rich Environmental Laboratory, Clemson University, 342 Computer Court, Anderson, SC 29625, USA

2 Department of Petroleum and Geosystems Engineering, University of Texas at Austin, 200 E Dean Keeton Street, Stop C0300, Austin, TX 78712, USA
Tween $\left.{ }^{\circledR} 20\right)$ and heavy $\left(2\right.$ CMC Tween $\left.{ }^{\circledR} 20\right)$ oil systems in terms of IFT trends. Concentrations below the $\mathrm{SiO}_{2} \mathrm{NP}$ threshold concentration resulted in a decrease in IFT, and concentrations above this threshold resulted in an increase in IFT. The IFT decreased until the NP concentration reached a threshold concentration where synergetic effects between nonionic surfactants and $\mathrm{SiO}_{2} \mathrm{NPs}$ are the opposite and result in antagonistic effects. Adsorption of both $\mathrm{SiO}_{2}$ NPs and surfactants at an interface caused a synergistic effect and an increased reduction in IFT. The effectiveness of the brine-surfactant- $\mathrm{SiO}_{2}$ nanofluids in decreasing the IFT between the oil-aqueous phase for the three tested crude oils were ranked as follows: (1) Prudhoe Bay $>$ (2) Lloydminster $>$ and (3) West Texas Intermediate. The level of asphaltenes and resins in these crude oil samples reflected these rankings. A decrease in the IFT also indicated the potential of the $\mathrm{SiO}_{2} \mathrm{NPs}$ to decrease capillary pressure and induce the movement and recovery of oil in original water-wet reservoirs. Conversely, an increase in IFT indicated the potential of $\mathrm{SiO}_{2}$ NPs to increase capillary pressure and oil recovery in reservoirs subject to wettability reversal under water-wet conditions. Raspberrylike morphology particles were discovered in $5 \mathrm{wt} \%$ brinesurfactant- $\mathrm{SiO}_{2}$ nanofluid-oil systems. The development of raspberry-like particles material with high surface area, high salt stability, and high capability of interfaces alteration and therefore wettability changes offers a wide range of applications in the fields of applied nanoscience, environmental engineering, and petroleum engineering.

Keywords Nanomaterials · Multiphase fluids - Interfacial processes · Adsorption · Crude oils · Tween ${ }^{\circledR} 20 \cdot$ Enhanced oil recovery $(\mathrm{EOR}) \cdot$ Raspberry-like morphology particles 


\section{Introduction}

Any efficient exploitation of new petroleum reservoirs necessitates developing methods to mobilize the crude oils from such reservoirs. The traditional oil recovery process consists of a primary and a secondary phase. The primary phase is induced by natural pressure which causes oil to flow from a reservoir. As pressure decreases beyond a specific threshold, the oil will no longer flow automatically from the reservoir. In order to increase pressure in the reservoir, during the secondary phase, gas or water is injected into the reservoir (Park et al. 2015). While most crude oil reservoirs are preferably oil-wet, the sweep efficiency associated with water flooding can be limiting which leads to difficulty in recovering crude oil during the secondary phase. Reports show that only $20-40 \%$ of crude oil is recovered with the primary and secondary recovery processes (Park et al. 2015; Hu et al. 2016a), indicating that more than half of the oil remains trapped in the reservoir. Capillary forces limit the mobility of oil in the reservoir during the primary and secondary recovery processes ( $\mathrm{Wu}$ et al. 2008). Capillary pressure, which is controlled by the wettability and interfacial tension (IFT) of the oil-water system, must be regulated to allow the flow and movement of oil through the pore network of the petroleum reservoir (Bear 1988). The displacement of oil in a reservoir is improved by increasing its mobility. Therefore, enhanced oil recovery (EOR) methods, including chemical EOR, have been created and implemented to mobilize oil and increase oil recovery from petroleum reservoirs. The wettability of petroleum reservoirs is a key factor in the oil recovery process. Altering the reservoir's wettability from oil-wet to water-wet conditions induces extreme changes in displacement mechanisms (Standnes and Austad 2000a, b; Strand et al. 2003, 2008; Somasundaran and Zhang 2006; Mohan et al. 2011; Ravari et al. 2011; Tabrizy et al. 2011; Wang et al. 2011; Park et al. 2015). The kinetics of wettability in an oil reservoir are governed by the surface activity of a surfactant, which is initially influenced by solution chemistry (Jadhunandan and Morrow 1995; Strand et al. 2008; Karimi et al. 2012). Specifically, wettability influences oil displacement in porous media, and the IFT of the oil-water system controls capillary forces, shape of oil drops, oil mobilization, and consequently oil recovery (Donaldson et al. 1989; Samanta et al. 2011; Roustaei and Bagherzadeh 2013).

In recent years, nanotechnology has offered a tremendous potential for petroleum engineering, in particular, for reservoir engineering (Amaya et al. 2002; Binks 2002; Fletcher and Davis 2010; Suleimanov et al. 2011; Wang et al. 2011; Hendraningrat et al. 2013; Kasel et al. 2013; Roustaei and Bagherzadeh 2013; Zhang et al. 2014;
Joonaki and Ghanaatian 2014; Biswal et al. 2016). Chemical agents, such as surfactants, are widely used as surface modifiers in chemical EOR to increase oil recovery. Nanoparticles are in turn coupled with surfactants as stabilizers of these diverse systems. Numerous studies have been performed to characterize the stability and mobility of nanoparticles in porous media. Specifically, the effects of the physico-chemical properties of nanoparticles and the solution chemistry of nanoparticle suspensions on their stability and mobility of nanoparticles in porous media have been investigated (Chen et al. 2004; Lecoanet and Wiesner 2004; Lecoanet et al. 2004; Espinasse et al. 2007; Wang et al. 2008a, b; Jaisi et al. 2008; Liu et al. 2009; Mattison et al. 2011; Godinez and Darnault 2011; Bouchard et al. 2012; O'Carroll et al. 2013; Hendraningrat et al. 2013; Kasel et al. 2013; Mekonen et al. 2014; Zargartalebi et al. 2015). For example, nanoparticle concentration, $\mathrm{pH}$, flow velocity, pore structure, and ionic strength impact the mobility of nanoparticles in porous media (Espinasse et al. 2007; Wang et al. 2008b; Uyusur et al. 2010; O'Carroll et al. 2013; Lanphere et al. 2014; Mekonen et al. 2014). Chemicals (e.g., surfactants and polymers) have been employed to control the aggregation of nanoparticles by stabilizing them in suspension and potentially enhancing their mobility in porous media (Fu and Sun 2003; Matarredona et al. 2003; Binks and Whitby 2005; Hyung et al. 2007; Uyusur et al. 2010; Godinez and Darnault 2011; Lin et al. 2012; Fang et al. 2013; Godinez et al. 2013; Lanphere et al. 2014). Surfactants produce thermodynamically stable nanoparticles through steric repulsion among nanoparticles, thereby reducing aggregation (Jiang et al. 2003; Chen et al. 2004; Ghadimi and Metselaar 2013). Surfactants also influence the interaction between nanoparticles and surfaces, flow hydrodynamics, and rheological properties of nanofluids (Uyusur et al. 2010; Godinez and Darnault 2011; Godinez et al. 2013; Yu et al. 2014; Pales et al. 2017).

Interfacial activities play a critical role in the behavior of many complex fluids. However, very few studies have been undertaken to investigate the interfacial behavior of oil-water systems in the presence of nanoparticles and surfactants. Consequently, although there is a limited understanding of the dynamics of a system when nanoparticles are present, the coexistence of a surfactant and nanoparticles may affect the surface activities of both surfactant and nanoparticles (Ravera et al. 2006, 2008). The ability of silicon dioxide nanoparticles $\left(\mathrm{SiO}_{2} \mathrm{NPs}\right)$ to alter the wettability of the reservoir and reduce the IFT between crude oil and brine has recently been applied to EOR (Elder et al. 2001; Eskandar et al. 2007; Roustaei and Bagherzadeh 2013, 2015; Zargartalebi et al. 2014; Hendraningrat and Torsæter 2015a, b; Biswal and Singh 2016; Sharma et al. 2016; Huibers et al. 2017). However, 
knowledge of the displacement efficiency of the $\mathrm{SiO}_{2} \mathrm{NPs}$ in EOR with different types of oil (light, medium, and heavy crude oils) is scarce. In their investigation of the influence of $\mathrm{SiO}_{2}$ NPs on the properties of the anionic surfactant sodium dodecyl sulfate (SDS), Zargartalebi et al. (2014) observed that the addition of $\mathrm{SiO}_{2}$ NPs affected the interfacial and adsorption properties of the surfactant. Opposite interfacial behaviors for oil and nano-augmented surfactant systems were also observed with low and high concentrations of the anionic surfactant. Ma et al. (2008) studied the effects of $\mathrm{SiO}_{2}$ NPs and non-ionic (Triton $\mathrm{X}-100$ ) and SDS surfactants on trichloroethylene (TCE)water interfaces. The addition of $\mathrm{SiO}_{2} \mathrm{NPs}$ slightly increased the efficiency of SDS at low concentrations and reduced IFT at TCE-water interfaces. However, $\mathrm{SiO}_{2} \mathrm{NPs}$ did not influence the IFT at TCE-water interfaces in the presence of Triton X-100. Electrostatic repulsion between negatively charged $\mathrm{SiO}_{2}$ NPs and SDS was established as the controlling factor of this IFT behavior. Ravera et al. (2006, 2008) reported on the effects of $\mathrm{SiO}_{2}$ NPs on the interfacial behavior between a cationic surfactant (CTAB, hexadecyltrimethylammonium bromide) and hexane. An increase in $\mathrm{SiO}_{2}$ NPs concentration in CTAB induced an increase in IFT between $\mathrm{SiO}_{2} \mathrm{NPs}-\mathrm{CTAB}$ and hexane. This phenomenon was attributed to the adsorption of CTAB on $\mathrm{SiO}_{2} \mathrm{NPs}$ and the resulting restructuring of the nanoparticle-surfactant layer.

Research on the effects of $\mathrm{ZrO}_{2}$ NPs on the interfacial behavior of surfactant solutions (i.e., SDS, lauryl alcohol 7 mol ethoxylate (nonionic), and dodecyl trimethyl ammonium bromide (cationic)) and n-hepthane-water interfaces demonstrated that below the critical micelle concentration (CMC) of the studied surfactants, increases in nanoparticle concentrations impacted the surface activity of the surfactant and induced a decrease in IFT (Esmaeilzadeh et al. 2014). However, no impact of $\mathrm{ZrO}_{2} \mathrm{NPs}$ on the IFT between the surfactant and n-hepthane was detected at or above the CMC of these surfactants. Lan et al. (2007) reported the synergistic effect of $\mathrm{SiO}_{2} \mathrm{NPs}$ and $\mathrm{CTAB}$ on the stability of oil-water emulsions. The established reduction effect of $\mathrm{SiO}_{2} \mathrm{NPs}$ on the IFT of oil-water in the presence of CTAB may be caused by the increase in surfactant adsorption due to electrostatic interactions between adsorbed particles and bulk surfactant molecules. Results also show that $\mathrm{SiO}_{2}$ NPs were adsorbed at the oilwater interface with an appropriate amount of $\mathrm{CTAB}$, but were desorbed into the bulk solution as flocs with excessive CTAB concentration. Interactions of $\mathrm{SiO}_{2} \mathrm{NPs}$ and surfactants (lecithin or oleylamine) at oil-water interfaces were studied for different polarities of oil phases (Miglyol ${ }^{\circledR} 812$ or liquid paraffin) (Eskandar et al. 2007). The concentration of $\mathrm{SiO}_{2}$ NPs governed the increase or decrease in the IFT of oil-water systems as a result of either attracting the surfactant to the oil-water interface or depleting the surfactant from the oil-water interface. As nanoparticles can self-assemble at the interface between oil and water systems, knowledge of the assembly and interactions between nanoparticles and surfactants is fundamental. Therefore, understanding the synergetic or antagonistic effects of nanoparticles on a surfactant is critical. However, sufficient information is unavailable about the properties of these nanoparticle-surfactant systems, such as their stability and interfacial behavior in association with various types of crude oil.

Understanding the mechanisms that govern the dynamics at these interfaces is a critical component of the management and exploitation of oil reservoirs. This understanding is essential for modifying the properties of nanofluids for specific fluid science and engineering applications, particularly the use of nanofluids in nanoparticle engineering for subsurface processes such as EOR. All of the possible factors (e.g., aggregation, surface charge, sedimentation of nanoparticles) have yet to be seriously considered in any study. Consequently, critical gaps remain in our knowledge of the IFT alterations of oilaqueous systems caused by nanoparticle dispersion in crude oil. Among the many nanoparticles that are utilized in EOR, metal oxide nanoparticles, such as $\mathrm{SiO}_{2} \mathrm{NPs}$, are of particular interest because $\mathrm{SiO}_{2}$ based nanofluids have been shown to significantly increase oil recovery yield during an EOR process (Hendraningrat and Torsæter 2014, 2015b; Griffith et al. 2016). In this context, the primary objectives of this research are to (1) explore the ability of $\mathrm{SiO}_{2}$ NPs to improve the efficiency of the chemical EOR that uses surfactant flooding, (2) investigate how varying $\mathrm{SiO}_{2}$ NPs and surfactant concentrations impact the stability of nanofluids and alter the IFT between nanofluids and crude oils for EOR—light crude oil, West Texas Intermediate; medium crude oil, Prudhoe Bay; and heavy crude oil, Lloydminster, and (3) establish the properties of crude oils that influence the dynamic and equilibrium behaviors of IFT at the oil-aqueous interface for brine-surfactant- $\mathrm{SiO}_{2}$ nanofluid-oil systems.

\section{Materials and methods}

\section{Nanoparticles}

Fumed silicon dioxide $\left(\mathrm{SiO}_{2}\right)$ nanopowder, supplied by PlasmaChem GmbH (Berlin, Germany) was used as the hydrophilic nanoparticle material. The material consists of more than $99.8 \% \mathrm{SiO}_{2}$ with an average nanoparticle size of $7-14 \mathrm{~nm}$, a bulk density of $0.048 \mathrm{~g} / \mathrm{cm}^{3}$, and a specific surface area over $200 \mathrm{~m}^{2} / \mathrm{g}$. 


\section{Surfactant}

The nonionic surfactant Tween $^{\circledR} 20$ was obtained from Sigma-Aldrich (USA). The critical micelle concentration (CMC) of Tween ${ }^{\circledR} 20$ is $60 \mathrm{mg} / \mathrm{L}$ with a density of $1.095 \mathrm{~g} /$ $\mathrm{mL}$ at $25^{\circ} \mathrm{C}$ and a molecular weight of $1228 \mathrm{~g} / \mathrm{mol}$. The hydrophile-lipophile balance (HLB) value for Tween ${ }^{\circledR} 20$ is 16.7.

\section{Crude oils}

Three types of crude oil (light oil, West Texas Intermediate (Environment Canada 2017a); medium oil, Prudhoe Bay (Environment Canada 2017b); and heavy oil, Lloydminster (Environment Canada 2017c) were used to simulate the oil phase. The physical and chemical properties of the crude oils are listed in Table 1.

\section{Nanofluid preparation}

Three stock solutions were prepared for the dispersion of nanofluids: a base aqueous fluid, consisting only of $5 \%$ brine (Tween ${ }^{\circledR} 20$ concentration of $0 \mathrm{CMC}$ ), and two brinesurfactant solutions with Tween ${ }^{\circledR} 20$ concentrations of 0.5 $\mathrm{CMC}$ and $2 \mathrm{CMC}$. The synthetic reservoir brine was the major component of the base aqueous fluid for nanoparticle dispersion. The $5 \mathrm{wt} \%$ brine base solution was prepared by adding $52.6316 \mathrm{~g}$ of $\mathrm{NaCl}$ (Fisher Scientific, Waltham, MA) into $1000 \mathrm{~mL}$ of ultrapure deionized (DI) water (resistivity $>18.2 \mathrm{M} \Omega \mathrm{cm}$, Millipore Corporation, Billerica, MA). The specified amounts of $\mathrm{NaCl}$ were weighted using a NewClassic MF analytical balance (Mettler Toledo, Columbus, $\mathrm{OH})$. The brine solution was completely mixed using a laboratory stirrer (Model PC-310, Corning Inc., Corning, NY) for $10 \mathrm{~min}$. The two brine-surfactant solutions were prepared by injecting two concentrations of Tween ${ }^{\circledR} 20,0.5 \mathrm{CMC}$ and $2 \mathrm{CMC}$, into $5 \mathrm{wt} \%$ brine solution. To make the $5 \mathrm{wt} \%$ brine with $0.5 \mathrm{CMC}$ Tween ${ }^{\circledR} 20$, $27.4 \mu \mathrm{L}$ Tween ${ }^{\circledR} 20$ was added to $1000 \mathrm{~mL} 5 \mathrm{wt} \%$ brine.
To generate the $5 \mathrm{wt} \%$ brine with $0.5 \mathrm{CMC}$ Tween ${ }^{\circledR} 20$, $109.6 \mu \mathrm{L}$ Tween ${ }^{\circledR} 20$ was added to $1000 \mathrm{~mL} 5 \mathrm{wt} \%$ brine.

A series of $\mathrm{SiO}_{2} \mathrm{NPs}$ concentrations were then dispersed in the three aqueous phases $(0,0.5$, and 2 CMC brinesurfactant solutions). Five $100 \mathrm{~mL}$ solutions of each brinesurfactant solution were transferred into $100 \mathrm{~mL}$ beakers. Stock suspensions of $\mathrm{SiO}_{2}$ NPs at concentrations of 0.001, $0.005,0.01,0.05$, and $0.1 \mathrm{wt} \%$ were then prepared according to the following dispersion protocol. Specific amounts of $\mathrm{SiO}_{2}$ NPs $(1,5,10.001,50.025$, and $100 \mathrm{mg})$ were weighed using an UMT2 ultra-microbalance (Mettler Toledo, Columbus, OH) in the Nano Enclosure $\mathrm{Xpert}^{\circledR}$, 38872 series (Labconco, Kansas City, MO) and then mixed with brine-surfactant solutions in the $100 \mathrm{~mL}$ beakers. Nanoparticle stock solutions with $0.001,0.005,0.01,0.05$, and $0.1 \mathrm{wt} \%$ concentrations, respectively, were produced, yielding a total of 18 different brine-surfactant-nanoparticle solutions (Table 2). Each of the nanofluid suspensions were sonicated by an ultrasonic liquid processor (Missonix, S-4000, Newton, CT), with an amplitude of 45 and a power strength of $40 \mathrm{~W}$ for 4 min before measuring the properties of the nanofluids (size, zeta potential, and sedimentation characteristics) and the IFT between the crude oil and the nanofluid.

\section{Characteristics of nanofluid systems}

\section{Size of $\mathrm{SiO}_{2}$ nanoparticles}

The z-average hydrodynamic diameter and size distribution of the $\mathrm{SiO}_{2} \mathrm{NP}$ aggregates in each nanofluid was determined by dynamic light scattering (DLS) using a 90Plus Zeta Particle Size Analyzer (Brookhaven Instruments Corporation, Holtsville, NY). Approximately $4 \mathrm{~mL}$ of the sonicated $\mathrm{SiO}_{2} \mathrm{NP}$ suspension was transferred to a small, transparent, four-sided cuvette made of polystyrene (light path $10 \mathrm{~mm}$, volume of $4.5 \mathrm{~mL}$ ) and inserted into a small slot in a 90Plus Zeta Particle Size Analyzer. Each solution was measured for $30 \mathrm{~min}$ continuously at $10 \mathrm{~s}$ intervals.

Table 1 Physico-chemical properties and hydrocarbon mass fractions of West Texas Intermediate (Environment Canada 2017a), Prudhoe Bay (Environment Canada 2017b), and Lloydminster (Environment Canada 2017c) crude oils

\begin{tabular}{|c|c|c|c|c|c|c|c|c|c|}
\hline Crude oil & Oil type & $\begin{array}{l}\text { Density }(\mathrm{g} / \mathrm{ml}) \\
\text { at } 15^{\circ} \mathrm{C}\end{array}$ & $\begin{array}{l}\text { Dynamic viscosity } \\
(\mathrm{mPa} \cdot \mathrm{s}) \text { at } 15{ }^{\circ} \mathrm{C}\end{array}$ & $\begin{array}{l}\text { API } \\
\text { gravity } \\
\left(^{\circ}\right)\end{array}$ & $\begin{array}{l}\text { Sulphur } \\
(\mathrm{wt} \%)\end{array}$ & $\begin{array}{l}\text { Saturates } \\
(\mathrm{wt} \%)\end{array}$ & $\begin{array}{l}\text { Aromatics } \\
(\mathrm{wt} \%)\end{array}$ & $\begin{array}{l}\text { Resins } \\
\text { (wt\%) }\end{array}$ & $\begin{array}{l}\text { Asphaltenes } \\
(\mathrm{wt} \%)\end{array}$ \\
\hline $\begin{array}{l}\text { West Texas } \\
\text { Intermediate }\end{array}$ & Light & $0.8212^{\mathrm{a}}$ & $7^{\mathrm{a}}$ & 40.8 & $0.34^{\mathrm{a}}$ & $66^{\mathrm{a}}$ & $26^{\mathrm{a}}$ & $6^{\mathrm{a}}$ & $1^{\mathrm{a}}$ \\
\hline Prudhoe Bay & Medium & $0.8837^{\mathrm{b}}$ & $22^{\mathrm{b}}$ & 28.5 & $0.96^{\mathrm{b}}$ & $53^{\mathrm{b}}$ & $34^{\mathrm{b}}$ & $10^{\mathrm{b}}$ & $4^{\mathrm{b}}$ \\
\hline Lloydminster & Heavy & $0.9020^{\mathrm{a}}$ & 63 & 20.7 & 3.15 & $68^{\mathrm{a}}$ & $22^{\mathrm{a}}$ & $4^{\mathrm{a}}$ & $6^{\mathrm{a}}$ \\
\hline
\end{tabular}

${ }^{\mathrm{a}}$ At evaporation (volume \%:0)

${ }^{\mathrm{b}}$ At evaporation (weight \%: 0) 
Table 2 The 18 nanofluid systems created for experimentation including three types of oil with six concentrations of nanoparticles either with or without surfactant

\begin{tabular}{|c|c|c|c|}
\hline \multirow[t]{2}{*}{ Oil type } & \multicolumn{3}{|c|}{ Surfactant and nanoparticle concentration } \\
\hline & $5 \%$ Brine & $5 \%$ Brine +0.5 CMC Tween ${ }^{\circledR} 20$ & $5 \%$ Brine +2 CMC Tween ${ }^{\circledR} 20$ \\
\hline \multirow{6}{*}{ West Texas Intermediate } & $0 \mathrm{wt} \% \mathrm{NP}$ & $0 \mathrm{wt} \% \mathrm{NP}$ & $0 \mathrm{wt} \% \mathrm{NP}$ \\
\hline & $0.001 \mathrm{wt} \% \mathrm{NP}$ & $0.001 \mathrm{wt} \% \mathrm{NP}$ & $0.001 \mathrm{wt} \% \mathrm{NP}$ \\
\hline & $0.005 \mathrm{wt} \% \mathrm{NP}$ & $0.005 \mathrm{wt} \% \mathrm{NP}$ & $0.005 \mathrm{wt} \% \mathrm{NP}$ \\
\hline & $0.01 \mathrm{wt} \% \mathrm{NP}$ & $0.01 \mathrm{wt} \% \mathrm{NP}$ & $0.01 \mathrm{wt} \% \mathrm{NP}$ \\
\hline & $0.05 \mathrm{wt} \% \mathrm{NP}$ & $0.05 \mathrm{wt} \% \mathrm{NP}$ & $0.05 \mathrm{wt} \% \mathrm{NP}$ \\
\hline & $0.1 \mathrm{wt} \% \mathrm{NP}$ & $0.1 \mathrm{wt} \% \mathrm{NP}$ & $0.1 \mathrm{wt} \% \mathrm{NP}$ \\
\hline \multirow[t]{6}{*}{ Prudhoe Bay } & $0 \mathrm{wt} \% \mathrm{NP}$ & $0 \mathrm{wt} \% \mathrm{NP}$ & $0 \mathrm{wt} \% \mathrm{NP}$ \\
\hline & $0.001 \mathrm{wt} \% \mathrm{NP}$ & $0.001 \mathrm{wt} \% \mathrm{NP}$ & $0.001 \mathrm{wt} \% \mathrm{NP}$ \\
\hline & $0.005 \mathrm{wt} \% \mathrm{NP}$ & $0.005 \mathrm{wt} \% \mathrm{NP}$ & $0.005 \mathrm{wt} \% \mathrm{NP}$ \\
\hline & $0.01 \mathrm{wt} \% \mathrm{NP}$ & $0.01 \mathrm{wt} \% \mathrm{NP}$ & $0.01 \mathrm{wt} \% \mathrm{NP}$ \\
\hline & $0.05 \mathrm{wt} \% \mathrm{NP}$ & $0.05 \mathrm{wt} \% \mathrm{NP}$ & $0.05 \mathrm{wt} \% \mathrm{NP}$ \\
\hline & $0.1 \mathrm{wt} \% \mathrm{NP}$ & $0.1 \mathrm{wt} \% \mathrm{NP}$ & $0.1 \mathrm{wt} \% \mathrm{NP}$ \\
\hline \multirow[t]{6}{*}{ Lloydminster } & $0 \mathrm{wt} \% \mathrm{NP}$ & $0 \mathrm{wt} \% \mathrm{NP}$ & $0 \mathrm{wt} \% \mathrm{NP}$ \\
\hline & $0.001 \mathrm{wt} \% \mathrm{NP}$ & $0.001 \mathrm{wt} \% \mathrm{NP}$ & $0.001 \mathrm{wt} \% \mathrm{NP}$ \\
\hline & $0.005 \mathrm{wt} \% \mathrm{NP}$ & $0.005 \mathrm{wt} \% \mathrm{NP}$ & $0.005 \mathrm{wt} \% \mathrm{NP}$ \\
\hline & $0.01 \mathrm{wt} \% \mathrm{NP}$ & $0.01 \mathrm{wt} \% \mathrm{NP}$ & $0.01 \mathrm{wt} \% \mathrm{NP}$ \\
\hline & $0.05 \mathrm{wt} \% \mathrm{NP}$ & $0.05 \mathrm{wt} \% \mathrm{NP}$ & $0.05 \mathrm{wt} \% \mathrm{NP}$ \\
\hline & $0.1 \mathrm{wt} \% \mathrm{NP}$ & $0.1 \mathrm{wt} \% \mathrm{NP}$ & $0.1 \mathrm{wt} \% \mathrm{NP}$ \\
\hline
\end{tabular}

The size measurement data were collected using the corresponding software, BIC Particle Sizing Software.

\section{Morphology of $\mathrm{SiO}_{2}$ nanoparticles}

Scanning electron microscope (SEM) was used to characterize the morphology of $\mathrm{SiO}_{2}$ nanoparticles. Scanning electron microscope (SEM) images of $\mathrm{SiO}_{2}$ nanoparticles of representative nanofluid systems were obtained using a Hitachi S-4800 SEM. SEM images of $\mathrm{SiO}_{2}$ nanoparticles were acquired under $4 \mathrm{kV}$ and $500 \mathrm{~nm}$ resolutions for the following nanofluid systems: (a) brine-0.001\% $\mathrm{SiO}_{2} \mathrm{NPs}$; (b) brine-0.5 CMC Tween ${ }^{\circledR} 20-0.001 \% \mathrm{SiO}_{2} \mathrm{NPs}$; (c) brine2 CMC Tween ${ }^{\circledR} 20-0.001 \% \quad \mathrm{SiO}_{2} \mathrm{NPs}$; (d) brine-0.01\% $\mathrm{SiO}_{2}$ NPs; (e) brine-0.5 CMC Tween ${ }^{\circledR} 20-0.01 \% \mathrm{SiO}_{2} \mathrm{NPs}$; (f) brine-2 CMC Tween ${ }^{\circledR} 20-0.01 \% \mathrm{SiO}_{2} \mathrm{NPs}$; (g) brine$0.1 \% \mathrm{SiO}_{2} \mathrm{NPs}$; (h) brine-0.5 CMC Tween ${ }^{\circledR} 20-0.1 \% \mathrm{SiO}_{2}$ NPs; and (i) brine-2 CMC Tween ${ }^{\circledR} 20-0.1 \% \mathrm{SiO}_{2}$ NPs.

\section{Zeta potential of $\mathrm{SiO}_{2}$ nanoparticles}

To measure the zeta potential of the $\mathrm{SiO}_{2} \mathrm{NP}$ aggregates for each nanofluid, $2 \mathrm{~mL}$ of the sonicated solution was transferred into a polystyrene cuvette and placed into a small slot in a 90Plus Zeta Particle Size Analyzer. Each solution was measured for $30 \mathrm{~min}$ continuously at $5 \mathrm{~min}$ intervals. The data for the zeta potential measurement were collected using a BIC PALS Zeta Potential Analyzer.

\section{Sedimentation of $\mathrm{SiO}_{2}$ nanoparticles}

Sedimentation characteristics of the $\mathrm{SiO}_{2}$ NPs suspensions were obtained from UV-Vis spectroscopy measurements using a Cary 300 Bio UV-Visible Spectrophotometer (formerly Varian, Walnut Creek, CA; now Agilent, Santa Clara, CA). UV-Vis measurements were conducted by placing the $\mathrm{SiO}_{2}$ NPs suspensions within a Spectrosil ${ }^{\circledR}$ spectrophotometer cell (VWR, Radnor, PA) with a dimension of $12.5 \mathrm{~W} \times 12.5 \mathrm{~L} \times 25 \mathrm{H} \mathrm{mm}$, volume of $0.7 \mathrm{~mL}$, and made of Spectrosil ${ }^{\circledR}$ quartz, which has a wavelength range of $170-2700 \mathrm{~nm}$ at $25^{\circ} \mathrm{C}$. Solutions without $\mathrm{SiO}_{2}$ NPs were used as blank solutions, and standard UV-Vis $\mathrm{SiO}_{2} \mathrm{NP}$ absorbance data were monitored to determine the sedimentation rate of the $\mathrm{SiO}_{2} \mathrm{NPs}$ under the influence of brine and Tween ${ }^{\circledR} 20$. UV-Vis measurements were carried out after sonication of the nanofluids. Data were collected every $10 \mathrm{~s}$ continuously for $30 \mathrm{~min}$. The evaluation of the stability of nanofluids was also conducted using direct visual observations of the nanoparticles in the brine-surfactant systems at different time intervals after sonication of each set of nanofluids $(0$, 20, and $30 \mathrm{~min}$ ). 


\section{Surface tension measurements of brine-surfactant-} $\mathrm{SiO}_{2}$ nanofluid systems and crude oils

Surface tension measurements were carried out with the DSA25 Drop Shape Analyzer (Kruss GmbH, Germany) in pendant drop mode with dynamic changes in surface tension tracked as a function of time for $30 \mathrm{~min}$ at 10 -s intervals. The sonicated nanofluids were placed in a plastic syringe $(1 \mathrm{~mL}$ NORM-JECT Tuberkulin syringe, Fisher Scientific, Waltman, MA) with a steel needle. A drop of nanofluid was suspended from the tip of the steel needle, and Data Shape Analysis software was used to track surface tension data between the air and the nanofluid every $10 \mathrm{~s}$ for $30 \mathrm{~min}$. During the measurement, the contour of the nanofluid drop image was extracted to calculate surface tension values by the Young-Laplace equation. The mean value of triplicate measurements was reported as a final surface tension value. The same procedure was used to measure the surface tension of the three oil types.

\section{Interfacial tension measurements of brine- surfactant-SiO ${ }_{2}$ nanofluid-oil systems}

The IFT between the crude oil drops and brine, brine-surfactant solutions, and $\mathrm{SiO}_{2}$ nanofluids was measured using the DSA25 Drop Shape Analyzer (Kruss GmbH, Germany) at $20{ }^{\circ} \mathrm{C}$ (Fig. 1a). $20 \mathrm{~mL}$ of sonicated solution was placed in a glass cuvette made with optical glass with an inner dimension of $36 \mathrm{~W} \times 36 \mathrm{D} \times 30 \mathrm{H} \mathrm{mm}$. Measurements were taken on oil droplets that were hanging from the tip of a syringe $(1 \mathrm{~mL}$ NORM-JECT Tuberkulin, Fisher Scientific, Waltman, MA) needle (J hook needle, $69 \mu \mathrm{m}$ diameter) (Fig. 1b). The Data Shape Analysis software was used to track IFT data as a function of time, every $10 \mathrm{~s}$ for $30 \mathrm{~min}$. During the measurement, the contour of the oil drop image was extracted to calculate IFT values by the Young-Laplace equation. Each IFT measurement was repeated three times for each brine, brine-surfactant solution, and $\mathrm{SiO}_{2}$ nanofluid using the three oil types.

\section{Statistical methods}

The outliers of the IFT values were removed from the triplicate data based on Eqs. (1) and (2) for each $30 \mathrm{~min}$ IFT data series:

Lower outlier $=Q_{1}-1.5 \mathrm{IQ}$,

Upper outlier $=Q_{3}+1.5 \mathrm{IQ}$,

where $Q_{1}=25$ th percentile, $Q_{3}=75$ th percentile, and $\mathrm{IQ}=Q_{3}-Q_{1}$ (interquartile range). After preprocessing, triplicate data were averaged to represent unique IFT data for each nanofluid system.

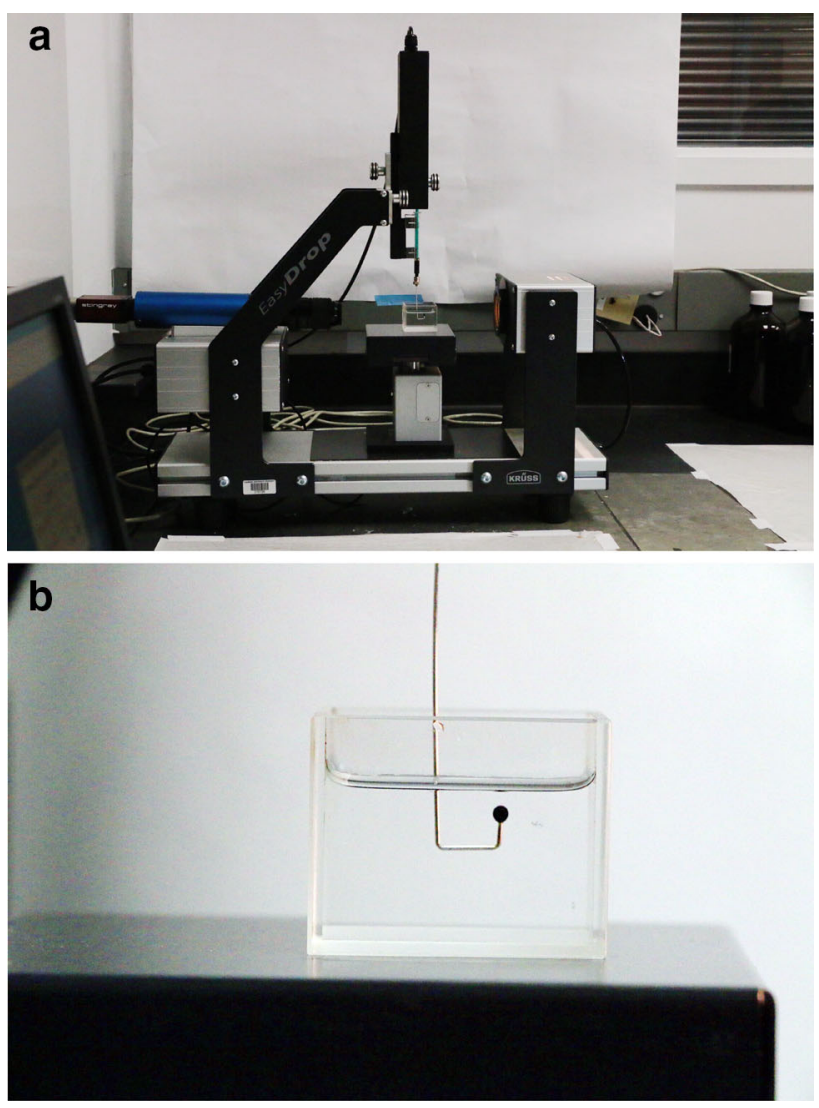

Fig. 1 Experimental equipment for interfacial tension (IFT) measurement (a) and visualization of drop of crude oil in $\mathrm{SiO}_{2}$ nanofluid for IFT measurement (b)

The Loess model was applied to oscillating IFT data to obtain a smooth curve with a span of 0.75 using R (Version 0.99.903-@ 2009-2016 RStudio, Inc.). To establish the IFT at equilibrium, the pivot time was determined for each system from the minimum of first derivatives calculated from the smoothed data. After the pivot time, the average and standard deviation of the equilibrium IFT were calculated. After removal of the outliers, all of the treatments were plotted in a smooth curve with a span of 0.75 with raw data for comparison.

\section{Results}

\section{Characteristics of nanofluid systems}

\section{Size and zeta potential of $\mathrm{SiO}_{2}$ nanoparticles}

The initial and equilibrium mean nanoaggregate size and the zeta potential of nanoparticle suspensions both with and without surfactant are shown in Fig. 2. The initial values were calculated by averaging the size and the zeta potential data from the first 1-min of $30 \mathrm{~min}$, and the equilibrium 
Fig. 2 Initial (I.) (open symbols) and equilibrium (E.) (solid symbols) behaviors of $\mathrm{SiO}_{2}$ nanoaggregate particle size (column) and zeta potential (scatter) for brine- $\mathrm{SiO}_{2}$ nanofluid samples with five $\mathrm{SiO}_{2}$ nanoparticle concentrations $(0.001 \mathrm{wt} \% \mathrm{NP}$, $0.005 \mathrm{wt} \% \mathrm{NP}, 0.01 \mathrm{wt} \% \mathrm{NP}$, $0.05 \mathrm{wt} \% \mathrm{NP}$, and $0.1 \mathrm{wt} \% \mathrm{NP})$ a without Tween ${ }^{\circledR} 20$ (0 CMC), b stabilized with $0.5 \mathrm{CMC}$ Tween ${ }^{\circledR} 20$, and $\mathbf{c}$ stabilized with 2 CMC Tween ${ }^{\circledR} 20$
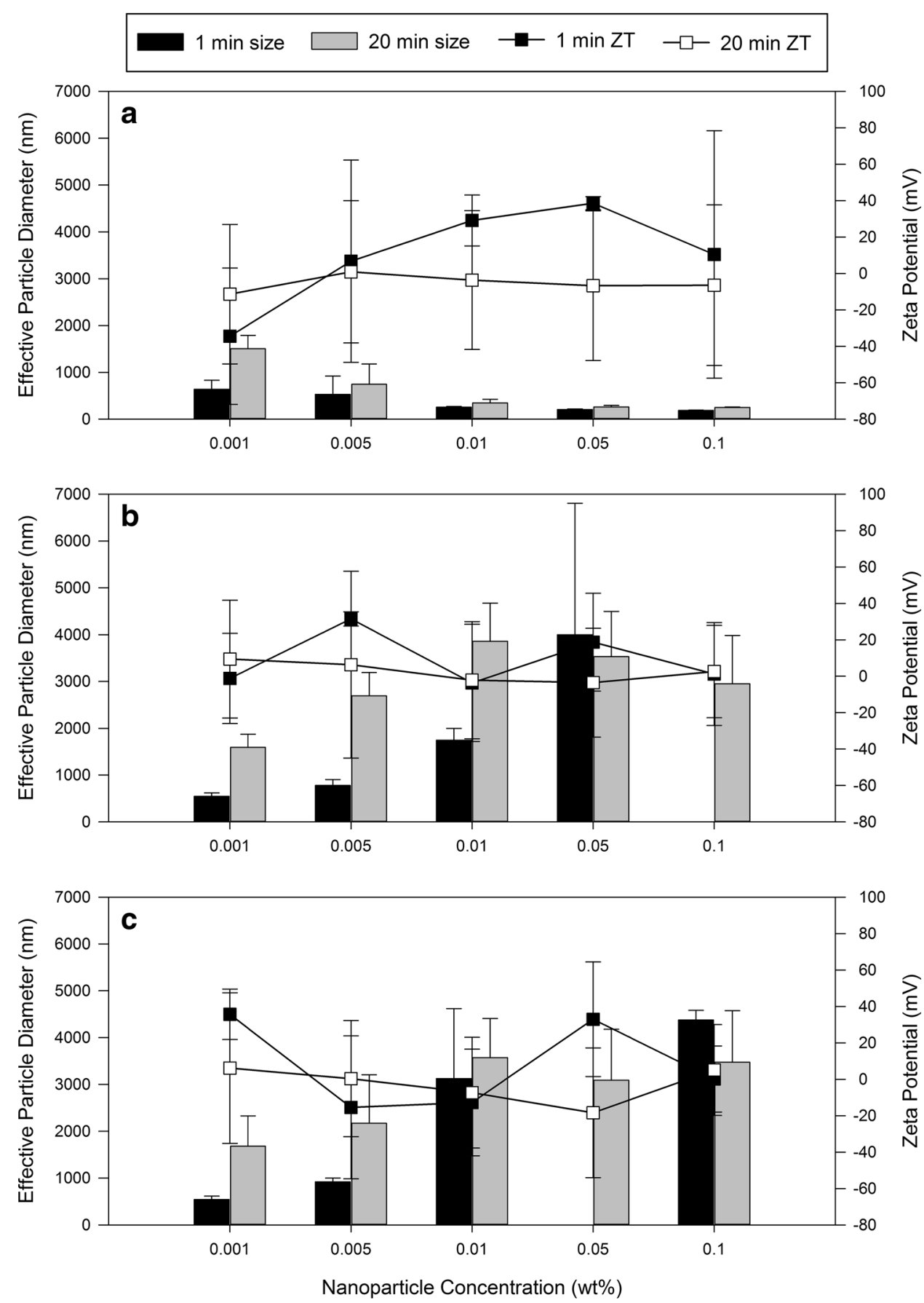

values were calculated by averaging the values collected between 20 and $30 \mathrm{~min}$.

The effective nanoaggregate diameter and zeta potential for nanofluids with 0.001 to $0.1 \mathrm{wt} \% \mathrm{SiO}_{2}$ NPs concentrations are shown in Fig. 2a. In the absence of surfactant, the size of the nanoaggregates decreased as a function of $\mathrm{SiO}_{2}$ NPs concentration until $0.1 \mathrm{wt} \%$ for both the initial and equilibrium stages. The effective particle diameter decreased from $639 \pm 193$ to $190 \pm 5 \mathrm{~nm}$ in the initial phase and was reduced from $1503 \pm 289$ to $249 \pm 12 \mathrm{~nm}$ in the equilibrium phase as nanoparticle concentration increased. The initial zeta potential value was $-34 \pm 37 \mathrm{mV}$ for the $0.001 \mathrm{wt} \%$ nanofluid. Upon increasing the nanoparticle concentration, the nanofluid with $0.005 \mathrm{wt} \% \mathrm{SiO}_{2} \mathrm{NPs}$ obtained a zeta potential of $7 \pm 56 \mathrm{mV}, 29 \pm 14 \mathrm{mV}$ at $0.01 \mathrm{wt} \%$, and $39 \pm 4 \mathrm{mV}$ at $0.05 \mathrm{wt} \%$. With a further increase in the concentration of nanoparticles to $0.1 \mathrm{wt} \%$, the zeta potential decreased to $10 \pm 68 \mathrm{mV}$. In the first $20 \mathrm{~min}$, the zeta potential changed dramatically as nanoparticle concentration increased, 
at which point the zeta potential values stabilized after $20 \mathrm{~min}$, at approximately $-10 \pm 40 \mathrm{mV}$ for the 0.001 , $0.01,0,05$ and $0.1 \mathrm{wt} \% \mathrm{SiO}_{2} \mathrm{NPs}$, and approximately $1 \pm 39 \mathrm{mV}$ for the $0.005 \mathrm{wt} \% \mathrm{SiO}_{2} \mathrm{NPs}$.

The initial and equilibrium size and zeta potential of the nanofluids stabilized by $0.5 \mathrm{CMC}$ and $2 \mathrm{CMC}$ Tween ${ }^{\circledR} 20$ are shown in Fig. $2 \mathrm{~b}$, c. In the presence of $0.5 \mathrm{CMC}$ Tween ${ }^{\circledR} 20$, the nanoaggregate size shows a steadily increasing trend at the initial stages from $546 \pm 70 \mathrm{~nm}$ at $0.001 \mathrm{wt} \% \mathrm{SiO}_{2} \mathrm{NPs}$ concentration to $3999 \pm 2807 \mathrm{~nm}$ at $0.05 \mathrm{wt} \%$. The size at $0.1 \mathrm{wt} \%$ was extremely high, beyond the measurement capability of the Zeta Particle Size Analyzer, and, thus, is not reported here. The nanofluids with $0.001 \mathrm{wt} \%$ to $0.01 \mathrm{wt} \% \mathrm{SiO}_{2} \mathrm{NPs}_{\text {concentration had }}$ larger particle sizes at the equilibrium stage than at the initial stage, increasing from $1593 \pm 282 \mathrm{~nm}$ to $3860 \pm 814 \mathrm{~nm}$. However, as nanoparticle concentration increased to $0.1 \mathrm{wt} \%, \mathrm{SiO}_{2} \mathrm{NPs}$, the nanoaggregate sizes were smaller at the equilibrium stage than at the initial stage, ranging from $3529 \pm 968$ to $2951 \pm 1034 \mathrm{~nm}$. During the initial phase, in a $0.5 \mathrm{CMC}$ Tween ${ }^{\circledR} 20$ nanofluid, zeta potential values tended to be unstable with increasing nanoparticle concentrations. The values were $-1 \pm 25,32 \pm 4,-4 \pm 32,19 \pm 27$ and $1 \pm 28 \mathrm{mV}$ for the $0.001 \mathrm{wt} \%$ brine-surfactant- $\mathrm{SiO}_{2}$ nanofluid through $0.01 \mathrm{wt} \%$, respectively. After $20 \mathrm{~min}$, all concentrations of nanofluids had a consistent zeta potential of approximately $1 \pm 30 \mathrm{mV}$.

The nanoaggregate size trend of the brine-surfactant$\mathrm{SiO}_{2}$ nanofluid is similar for the $0.5 \mathrm{CMC}$ and the $2 \mathrm{CMC}$ Tween ${ }^{\circledR} 20$ concentrations. At 2 CMC Tween ${ }^{\circledR} 20$, the initial nanoaggregate size increased from $543 \pm 71 \mathrm{~nm}$ to $3126 \pm 1492 \mathrm{~nm}$ for the $0.001 \mathrm{wt} \%$ and the $0.01 \mathrm{wt} \%$, respectively, and then decreased from a size over $6000 \mathrm{~nm}$ at $0.05 \mathrm{wt} \%$ to $4375 \pm 207 \mathrm{~nm}$ at $0.1 \mathrm{wt} \%$. At the equilibrium stage, the $0.001 \mathrm{wt} \%$ through the $0.01 \mathrm{wt} \%$ had larger nanoaggregate sizes than at the initial stage, ranging from $3572 \pm 835 \mathrm{~nm}$ to $1680 \pm 648 \mathrm{~nm}$, respectively. At $0.05 \mathrm{wt} \%$, the nanoaggregate size decreased to $3088 \pm 1087 \mathrm{~nm}$ at the equilibrium stage. At a nanoparticle concentration of $0.1 \mathrm{wt} \%$, the nanoaggregate size at the equilibrium stage was $3473 \pm 1099 \mathrm{~nm}$. The zeta potential of 2 CMC Tween ${ }^{\circledR} 20$ brine-surfactant-SiO ${ }_{2}$ nanofluid with nanoparticle concentration between 0.001 and $0.1 \mathrm{wt} \%$ was unstable with values of $39 \pm 14$, $-15 \pm 39, \quad-12 \pm 29, \quad 33 \pm 31$ and $0 \pm 18 \mathrm{mV}$, respectively. Zeta potentials for these solutions became stable after $20 \mathrm{~min}$ with a value of approximately $3 \pm 32 \mathrm{mV}$.

The histograms of the size distribution of $\mathrm{SiO}_{2}$ nanoparticles of the different nanofluid systems are shown in Fig. 3. In brine- $\mathrm{SiO}_{2} \mathrm{NP}$ systems, the lowest concentrations of nanoparticles $(0.001$ and $0.005 \mathrm{wt} \%)$ generated a polydisperse size distribution while higher concentrations produced a monodisperse size distribution of $\mathrm{SiO}_{2} \mathrm{NPs}$, in the case of the size distributions built from DLS measurements for $1 \mathrm{~min}$ and 20-30 min. In the brine-0.5 CMC Tween ${ }^{\circledR} 20-\mathrm{SiO}_{2} \mathrm{NP}$ and the brine-2 CMC Tween ${ }^{\circledR} 20-\mathrm{SiO}_{2}$ NP systems, similar findings were observed, except that the range of $\mathrm{SiO}_{2} \mathrm{NP}$ concentrations for which a polydisperse size distribution was observed encompassed 0.001, 0.005 and $0.01 \mathrm{wt} \% \mathrm{SiO}_{2}$ NPs.

\section{Morphology of $\mathrm{SiO}_{2}$ nanoparticles}

SEM images of $\mathrm{SiO}_{2}$ nanoparticles are presented in Fig. 4. It can be seen that $\mathrm{SiO}_{2}$ nanoparticles at 0.001, 0.01, and $0.1 \mathrm{wt} \%$ formed aggregates in the brine- $\mathrm{SiO}_{2}$ nanofluid systems and the brine-surfactant- $\mathrm{SiO}_{2}$ nanofluid systems. SEM images show an assemblage of $\mathrm{SiO}_{2}$ nanoparticles where large particles are covered by small ones (Fig. 4). SEM confirms the raspberry-like morphology particles of these assemblages of $\mathrm{SiO}_{2}$ nanoparticles.

\section{Sedimentation of $\mathrm{SiO}_{2}$ nanoparticles}

The sedimentation study of the brine-surfactant- $\mathrm{SiO}_{2}$ nanofluids monitored by UV-Vis spectrophotometer is based on an initial wavelength reading of $204 \mathrm{~nm}$. The sedimentation results at the initial and equilibrium stages of the nanoaggregates in 15 nanofluids with $\mathrm{SiO}_{2}$ NPs concentrations from 0.001 to $0.1 \mathrm{wt} \%$ are shown in Fig. 5 in the absence and presence of $0.5 \mathrm{CMC}$ and $2 \mathrm{CMC}$ Tween ${ }^{\circledR} 20$. In the absence of Tween ${ }^{\circledR} 20$ in all nanofluids, the initial sedimentation ratio was approximately 0.1 , however, after adding Tween ${ }^{\circledR} 20$, the sedimentation ratio increased. The initial sedimentation ratio for the first minute after monitoring, which is calculated as an average of the measurements, was approximately 0.1 for all solutions. Although very little sedimentation occurred in the first minute, high sedimentation rates were recorded between 20 and 30 min after monitoring began. The sedimentation ratio was 0.5 at $0.001 \mathrm{wt} \%, 0.8$ at $0.005 \mathrm{wt} \%, 0.7$ at $0.0 .01 \mathrm{wt} \%$ and $0.05 \mathrm{wt} \%$, and back to 0.5 at $0.1 \mathrm{wt} \%$.

The sedimentation ratios for nanofluids with 0.001 to 0.01 wt $\%$ with $0.5 \mathrm{CMC}$ Tween ${ }^{\circledR} 20$ were relatively constant at approximately 0.7 with an increase to 0.9 at 0.05 wt $\%$ which then remained constant until $0.1 \mathrm{wt} \%$. Adding 2 CMC Tween ${ }^{\circledR} 20$ did not produce any significant changes in sedimentation, with slightly higher sedimentation ratios found in the $0.5 \mathrm{CMC}$ Tween ${ }^{\circledR} 20$ brine-surfactant- $\mathrm{SiO}_{2}$ nanofluids. The evaluation of the stability of nanofluids conducted using direct visual observations of the nanoparticles in the brine-surfactant systems at different time intervals after sonication of each set of nanofluids $(0$, 

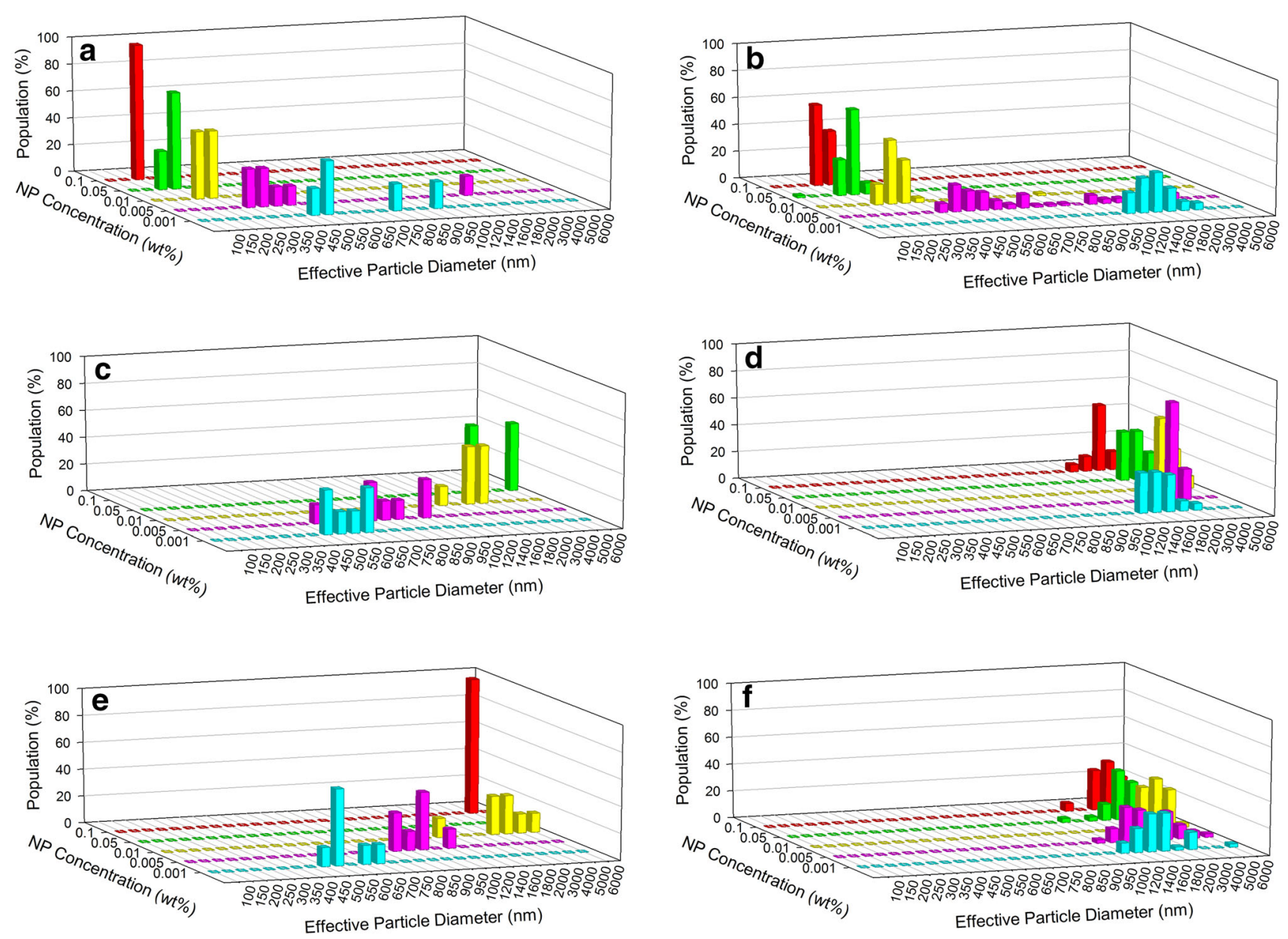

\section{$0.001 \mathrm{wt} \% \mathrm{NP}=0.005 \mathrm{wt} \% \mathrm{NP}$}

Fig. 3 Histograms of size distribution of $\mathrm{SiO}_{2}$ nanoparticles built from dynamic light scattering measurements for five $\mathrm{SiO}_{2}$ nanoparticle concentrations $(0.001 \mathrm{wt} \% \mathrm{NP}, 0.005 \mathrm{wt} \% \mathrm{NP}, 0.01 \mathrm{wt} \% \mathrm{NP}$, $0.05 \mathrm{wt} \% \mathrm{NP}$, and $0.1 \mathrm{wt} \% \mathrm{NP})$, in: a brine- $\mathrm{SiO}_{2} \mathrm{NP}$ systems within $1 \mathrm{~min}$; b brine- $\mathrm{SiO}_{2} \mathrm{NP}$ systems at $20-30 \mathrm{~min}$; c brine- $0.5 \mathrm{CMC}$

Tween ${ }^{\circledR} 20-\mathrm{SiO}_{2}$ NP systems within $1 \mathrm{~min} ;$ d brine-0.5 CMC Tween ${ }^{\circledR} 20-\mathrm{SiO}_{2}$ NP systems at $20-30 \mathrm{~min}$; e brine-2 CMC Tween ${ }^{\circledR} 20-\mathrm{SiO}_{2}$ NP systems within $1 \mathrm{~min}$; d brine-2 CMC Tween ${ }^{\circledR} 20-\mathrm{SiO}_{2} \mathrm{NP}$ systems at $20-30 \mathrm{~min}$

20, and $30 \mathrm{~min}$ ) support the sedimentation results and the stability of the nanofluids (Table 3 ).

\section{Surface tension of nanofluids}

The surface tension of 15 nanofluids with increasing $\mathrm{SiO}_{2}$ NPs concentration from 0.001 to $0.1 \mathrm{wt} \%$ is shown in Fig. 6 for all three surfactant concentrations of 0 CMC, 0.5 $\mathrm{CMC}$, and $2 \mathrm{CMC}$. In the absence of Tween ${ }^{\circledR} 20$, the surface tension for the nanofluids increased from $61 \mathrm{mN} / \mathrm{m}$ at $0.001 \mathrm{wt} \% \mathrm{SiO}_{2} \mathrm{NPs}$ to $72 \mathrm{mN} / \mathrm{m}$ at $0.1 \mathrm{wt} \% \mathrm{SiO}_{2} \mathrm{NPs}$ during the initial stage; after $20 \mathrm{~min}$, the values for the $0.001 \mathrm{wt} \%$ and $0.01 \mathrm{wt} \%$ increased from $65 \mathrm{mN} / \mathrm{m}$ to 76 $\mathrm{mN} / \mathrm{m}$, respectively. At a $\mathrm{SiO}_{2} \mathrm{NPs}$ concentration of 0.1

wt $\%$, the surface tension decreased to $66 \mathrm{mN} / \mathrm{m}$. After adding 0.5 CMC surfactant, the initial surface tensions for the 0.001 and $0.1 \mathrm{wt} \%$ brine-surfactant- $\mathrm{SiO}_{2}$ nanofluids increased from 41 to $52 \mathrm{mN} / \mathrm{m}$, and at equilibrium stage, the values increased from 35 to $45 \mathrm{mN} / \mathrm{m}$. With surfactant concentrations as high as $2 \mathrm{CMC}$, the initial stage surface tensions of the brine-surfactant- $\mathrm{SiO}_{2}$ nanofluids ranged from 37 to $46 \mathrm{mN} / \mathrm{m}$. Over $20 \mathrm{~min}$, the surface tensions were $47,33,42,35$, and $40 \mathrm{mN} / \mathrm{m}$ corresponding to brinesurfactant- $\mathrm{SiO}_{2}$ nanofluids with nanoparticle concentration between 0.001 and $0.1 \mathrm{wt} \%$, respectively. Average values of surface tension of crude oils measured over 30 min were $26.50 \mathrm{mN} / \mathrm{m}$ for West Texas Intermediate, $29.45 \mathrm{mN} / \mathrm{m}$ for Prudhoe Bay, and $29.25 \mathrm{mN} / \mathrm{m}$ for Lloydminster. 


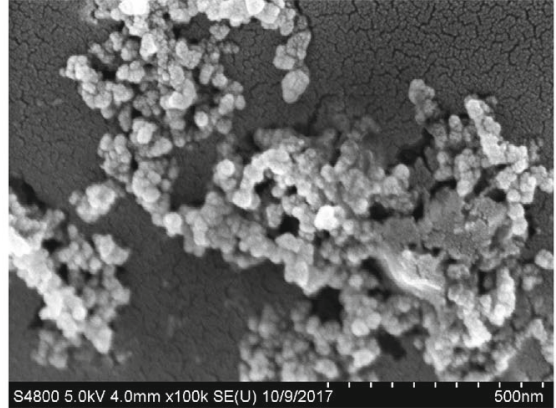

(a)

Brine-0.001 wt\% $\mathrm{SiO}_{2}$ NPs

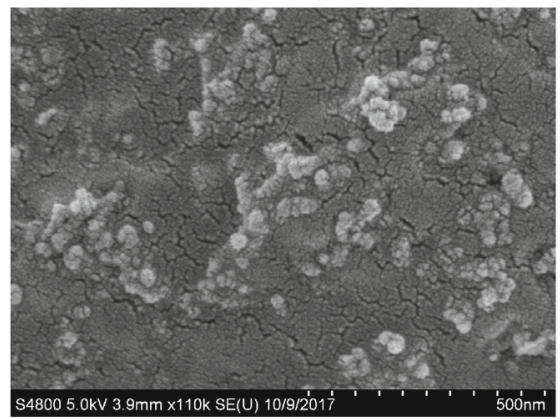

(d)

Brine- 0.01 wt $\% \mathrm{SiO}_{2} \mathrm{NPs}$

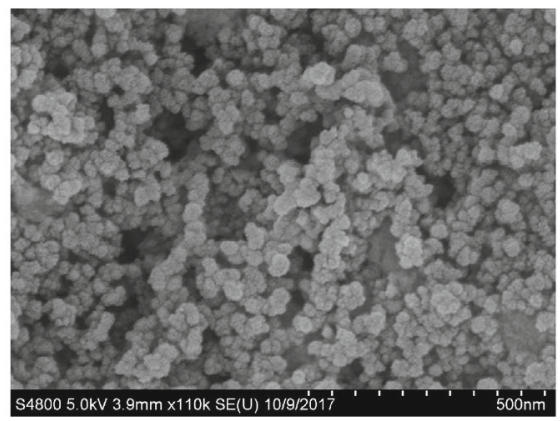

(g)

Brine-0.1 wt $\% \mathrm{SiO}_{2} \mathrm{NPs}$

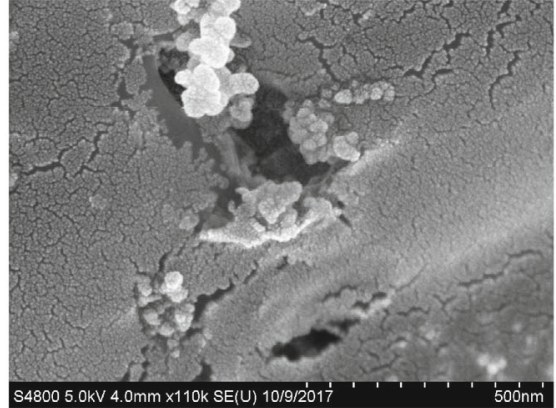

(b)

Brine-0.5 CMC Tween ${ }^{\otimes} 20-0.001$ wt $\% \mathrm{SiO}_{2}$ NPs

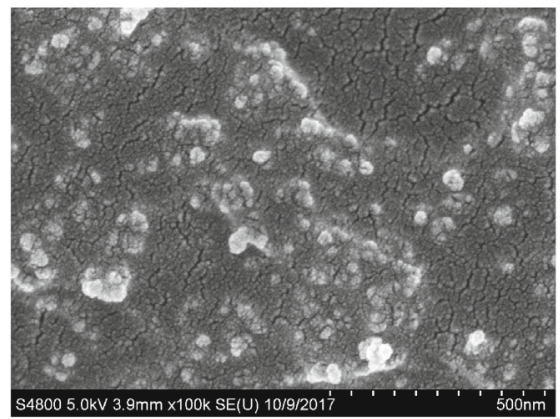

(e)

Brine-0.5 CMC Tween ${ }^{\otimes} 20-0.01$ wt $\% \mathrm{SiO}_{2}$ NPs

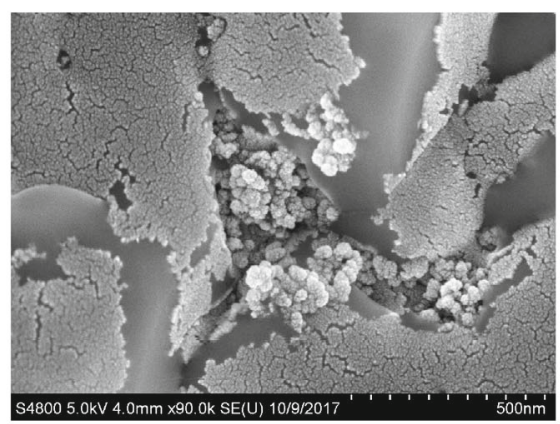

(h)

Brine-0.5 CMC Tween ${ }^{\otimes} 20-0.1$ wt $\% \mathrm{SiO}_{2}$ NPs

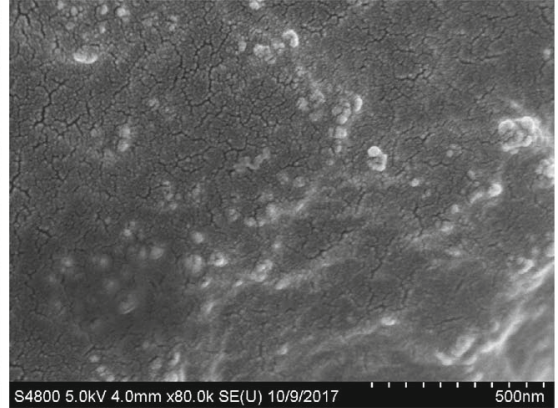

(c)

Brine-2 CMC Tween ${ }^{\otimes} 20-0.001$ wt $\% \mathrm{SiO}_{2}$ NPs

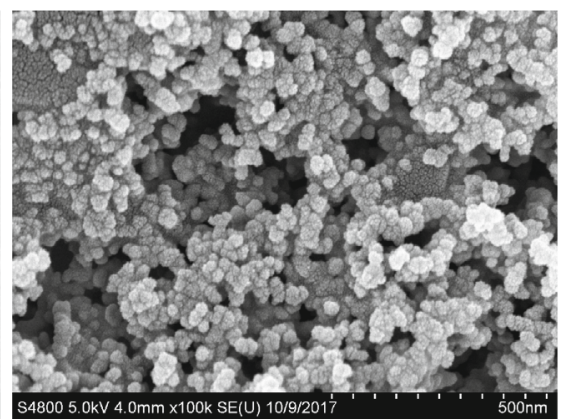

(f)

Brine-2 CMC Tween ${ }^{\circledR 20-0.01 ~ w t \% ~} \mathrm{SiO}_{2}$ NPs

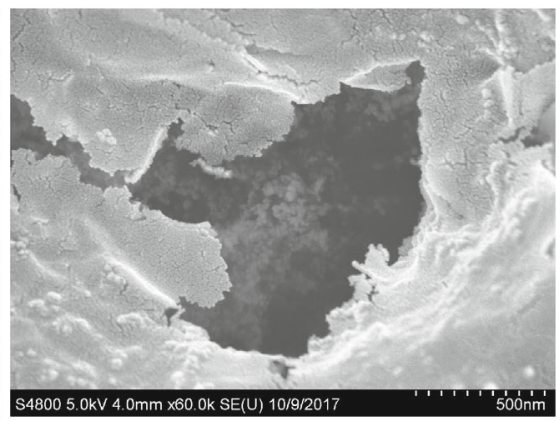

(i)

Brine-2 CMC Tween ${ }^{\otimes} 20-0.1$ wt $\% \mathrm{SiO}_{2}$ NPs
Fig. 4 SEM images of $\mathrm{SiO}_{2}$ nanoparticles for: a brine-0.001 wt $\%$ $\mathrm{SiO}_{2} \mathrm{NPs} ; \mathbf{b}$ brine- $0.5 \mathrm{CMC}$ Tween ${ }^{\circledR} 20-0.001 \mathrm{wt} \% \mathrm{SiO}_{2} \mathrm{NPs} ; \mathbf{c}$ brine2 CMC Tween ${ }^{\circledR} 20-0.001 \mathrm{wt} \% \mathrm{SiO}_{2} \mathrm{NPs} ; \mathbf{d}$ brine- $0.01 \mathrm{wt} \% \mathrm{SiO}_{2} \mathrm{NPs}$; e brine-0.5 CMC Tween ${ }^{\circledR} 20-0.01 \mathrm{wt} \% \quad \mathrm{SiO}_{2} \mathrm{NPs}$; f brine-2 CMC

\section{Interfacial tension between brine-surfactant-SiO ${ }_{2}$ NPs systems and crude oils}

\section{Light crude oil}

The visual observation of the interface between brine-surfactant- $\mathrm{SiO}_{2}$ NPs systems and drops of West Texas Intermediate light crude oil are shown in Table 4. The IFT between brine- $\mathrm{SiO}_{2}$ NPs systems and a light crude oil, West Texas Intermediate crude oil, as a function of time is shown in Fig. 7a. A smoothing function based on a Loess
Tween ${ }^{\circledR} 20-0.01$ wt $\% \mathrm{SiO}_{2}$ NPs; $\mathbf{g}$ brine-0.1 wt $\% \mathrm{SiO}_{2}$ NPs; $\mathbf{h}$ brine0.5 CMC Tween ${ }^{\circledR} 20-0.1$ wt $\% \mathrm{SiO}_{2}$ NPs; $\mathbf{i}$ brine-2 CMC Tween ${ }^{\circledR} 20-$ $0.1 \mathrm{wt} \% \mathrm{SiO}_{2} \mathrm{NPs}$

Model in $\mathrm{R}$ to remove the outliers from Fig. 7a was then used to generate Fig. 7b. A dynamic influence of time on IFT was observed in all systems. The monitoring of the IFTs between brine-SiO $\mathrm{S}_{2}$ NPs systems and West Texas Intermediate as a function of time indicated a decrease in IFT. The IFT curve first showed a sharp decrease with values decreasing from $18.54-21.87 \mathrm{mN} / \mathrm{m}$ to $14.10-15.64$ $\mathrm{mN} / \mathrm{m}$. A plateau was then observed with values remaining stable at $14.10-15.64 \mathrm{mN} / \mathrm{m}$, indicating that the IFT stabilized and reached the equilibrium stage after the pivot time. The reference IFT of the brine-oil system $(0 \mathrm{wt} \%$ 


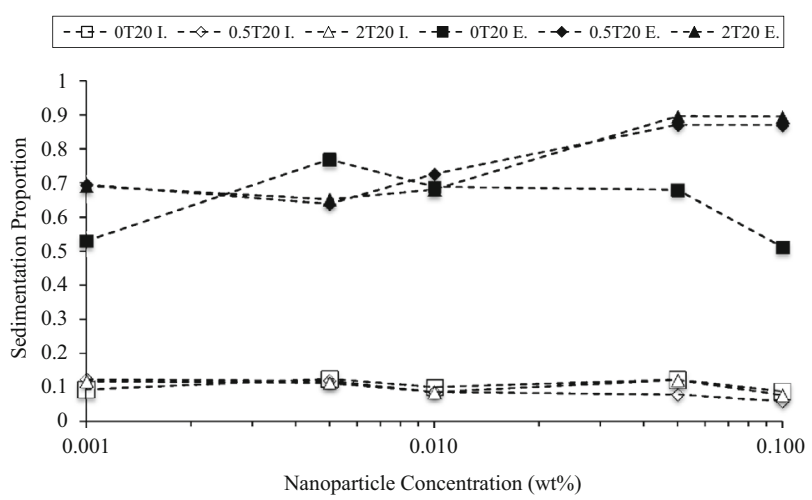

Fig. 5 Initial (I.) (open symbols) and equilibrium (E.) (solid symbols) behaviors of the sedimentation proportion of brine- $\mathrm{SiO}_{2}$ nanofluids with five $\mathrm{SiO}_{2}$ nanoparticle concentrations (0.001 wt\% NP, $0.005 \mathrm{wt} \% \mathrm{NP}, 0.01 \mathrm{wt} \% \mathrm{NP}, 0.05 \mathrm{wt} \% \mathrm{NP}$, and $0.1 \mathrm{wt} \% \mathrm{NP})$ without Tween ${ }^{\circledR} 20$ (square symbols), in the presence of 0.5 CMC Tween ${ }^{\circledR} 20$ (diamond symbols), and in the presence of 2 CMC Tween ${ }^{\circledR} 20$ (triangle symbols)

$\mathrm{SiO}_{2} \mathrm{NPs}$ ) at equilibrium was $14.35 \mathrm{mN} / \mathrm{m}$, with the $\mathrm{SiO}_{2}$ NP concentrations exhibiting a slight effect of the IFT of the brine-oil systems. The addition of $\mathrm{SiO}_{2} \mathrm{NPs}$ exhibited the opposite effects on the equilibrium IFT values, which depend upon the concentration of $\mathrm{SiO}_{2}$ NPs in the nanofluid-oil systems compared to the concentration of the reference. The $\mathrm{SiO}_{2}$ NPs concentrations of 0.001 and 0.01 wt $\%$ had slightly decreased IFT values of 14.10 and 14.22 $\mathrm{mN} / \mathrm{m}$, respectively, while the $\mathrm{SiO}_{2} \mathrm{NP}$ concentrations of $0.005,0.05$, and $0.1 \mathrm{wt} \%$ resulted in small increases in IFT, with values reaching $14.47,15.19$, and $15.64 \mathrm{mN} / \mathrm{m}$, respectively.

The IFT dynamics between the brine-surfactant- $\mathrm{SiO}_{2}$ NP systems and West Texas Intermediate crude oil in the presence of Tween ${ }^{\circledR} 20$ at 0.5 and 2 CMC, respectively, is shown in Fig. 7c, e. The processed data using a smooth functioning on the Loess Model in R is shown in Fig. 7d, f. A similar dynamic trend was observed for the IFT of the brine-surfactant- $\mathrm{SiO}_{2}$ nanofluid-oil systems as in the systems where surfactant was absent. IFT values decreased rapidly and then reached a plateau. The Initial IFT values for the brine-surfactant- $\mathrm{SiO}_{2}$ nanofluid-oil systems with Tween ${ }^{\circledR} 20$ at 0.5 and $2 \mathrm{CMC}$ fell within a range of 7.06 to $18.20 \mathrm{mN} / \mathrm{m}$ and from 8.82 to $13.86 \mathrm{mN} / \mathrm{m}$, respectively, with the lowest IFT values occurring for $0 \mathrm{wt} \% \mathrm{SiO}_{2} \mathrm{NP}$. The presence of Tween ${ }^{\circledR} 20$ at 0.5 and 2 CMC significantly reduced the IFTs between the oil and brine-surfactant and the oil and brine-surfactant $\mathrm{SiO}_{2} \mathrm{NPs}$ compared to the same systems without surfactant. However, the concentration of $\mathrm{SiO}_{2} \mathrm{NPs}$ did affect the IFT of these systems. Specifically an increase in the $\mathrm{SiO}_{2}$ NPs concentration in the brinesurfactant- $\mathrm{SiO}_{2}$ nanofluid-oil systems caused a corresponding increase in the IFT of these systems at equilibrium (Fig. 8). The average IFT values at equilibrium ranged from $3.97 \mathrm{mN} / \mathrm{m}\left(0 \mathrm{wt} \% \mathrm{SiO}_{2} \mathrm{NP}\right)$ to $9.42 \mathrm{mN} / \mathrm{m}$ $\left(0.1 \mathrm{wt} \% \mathrm{SiO}_{2} \mathrm{NPs}\right)$, and $4.22 \mathrm{mN} / \mathrm{m}\left(0 \mathrm{wt} \% \mathrm{SiO}_{2} \mathrm{NP}\right)$ to $12.73 \mathrm{mN} / \mathrm{m}\left(0.1 \mathrm{wt} \% \mathrm{SiO}_{2} \mathrm{NPs}\right)$ for brine-surfactant- $\mathrm{SiO}_{2}$ nanofluid-oil systems with Tween ${ }^{\circledR} 20$ at 0.5 and $2 \mathrm{CMC}$, respectively; the lowest IFT values for the 0.5 and $2 \mathrm{CMC}$ Tween ${ }^{\circledR} 20$ systems occurred for those without nanoparticles $\left(0 \mathrm{wt} \% \mathrm{SiO}_{2} \mathrm{NP}\right)$.

\section{Medium crude oil}

The visual observation of the interface between brine-surfactant- $\mathrm{SiO}_{2}$ NPs systems and drops of Prudhoe Bay medium crude oil are shown in Table 5. The IFT dynamics between $\mathrm{SiO}_{2}$ NPs systems and Prudhoe Bay medium crude oil is shown in Fig. 9a, and the processed data, developed with a smoothing function based on a Loess Model in R, is shown in Fig. 9b. The dynamic change trend in IFT varies with that of the $\mathrm{SiO}_{2} \mathrm{NP}$ concentration. The reference IFT of the brine-oil system remained quite stable over time with an initial IFT of $17.55 \mathrm{mN} / \mathrm{m}$ and equilibrium IFT of $18.25 \mathrm{mN} / \mathrm{m}$. However, the addition of $\mathrm{SiO}_{2}$ NPs to the brine resulted in a significant decrease in all IFTs between the brine- $\mathrm{SiO}_{2} \mathrm{NP}$ systems and Prudhoe Bay crude oil, regardless of the $\mathrm{SiO}_{2} \mathrm{NP}$ concentration. The $\mathrm{SiO}_{2} \mathrm{NP}$ concentrations of 0.005 and $0.05 \mathrm{wt} \%$ stabilized the IFTs over time, with equilibrium IFTs of 13.16 and $13.11 \mathrm{mN} / \mathrm{m}$, respectively. The $\mathrm{SiO}_{2} \mathrm{NP}$ concentrations of $0.001,0.01$ and $0.1 \mathrm{wt} \%$ showed a decrease in IFT values over time, with the lowest IFT value occurring at equilibrium $10.40 \mathrm{mN} / \mathrm{m}$ with an $\mathrm{SiO}_{2} \mathrm{NP}$ level of 0.001 wt $\%$.

The IFT dynamics between brine-surfactant- $\mathrm{SiO}_{2} \mathrm{NPs}$ systems and Prudhoe Bay crude oil is shown in Fig. 9c, e. The processed data, developed from a smoothing function based on the Loess Model in $\mathrm{R}$ in the presence of Tween ${ }^{\circledR} 20$ at $0.5 \mathrm{CMC}$ and $2 \mathrm{CMC}$, is shown in Fig. $9 \mathrm{~d}$, f. The IFT dynamics between brine-surfactant- $\mathrm{SiO}_{2}$ NPs systems and Prudhoe Bay crude oil showed two trends depending on the concentration of $\mathrm{SiO}_{2}$ NPs. The initial IFTs values ranged from 9.73 to $17.59 \mathrm{mN} / \mathrm{m}$ and from 8.01 to $13.58 \mathrm{mN} / \mathrm{m}$. With Tween ${ }^{\circledR} 20$ at $0.5 \mathrm{CMC}$, the $\mathrm{SiO}_{2} \mathrm{NP}$ concentrations of $0 \mathrm{wt} \%$, and $0.01 \mathrm{wt} \%$ induced a decrease in IFT to reach equilibrium. The lowest equilibrium IFT value, $5.45 \mathrm{mN} / \mathrm{m}$, for the brine-surfactant- $\mathrm{SiO}_{2}$ NPs systems and Prudhoe Bay crude oil for Tween ${ }^{\circledR} 20$ at 0.5 CMC was obtained with $0.001 \mathrm{wt} \%$, while for Tween ${ }^{\circledR} 20$ at $2 \mathrm{CMC}$ it was achieved with $0.005 \mathrm{wt} \%$ of $\mathrm{SiO}_{2} \mathrm{NPs}$, which was $5.81 \mathrm{mN} / \mathrm{m}$. The 0.05 wt $\%$ concentration with Tween ${ }^{\circledR} 20$ at $0.5 \mathrm{CMC}$ induced an increase in IFTs with equilibrium values reaching $16.40 \mathrm{mN} / \mathrm{m}$. All six $\mathrm{SiO}_{2}$ NPs concentrations with Tween ${ }^{\circledR} 20$ at $2 \mathrm{CMC}$ induced significant decreases in IFT over time, especially the $0.05 \mathrm{wt} \%$ concentration with Tween ${ }^{\circledR} 20$ at $2 \mathrm{CMC}$, 
Table 3 Visual observation of nanofluid systems stability

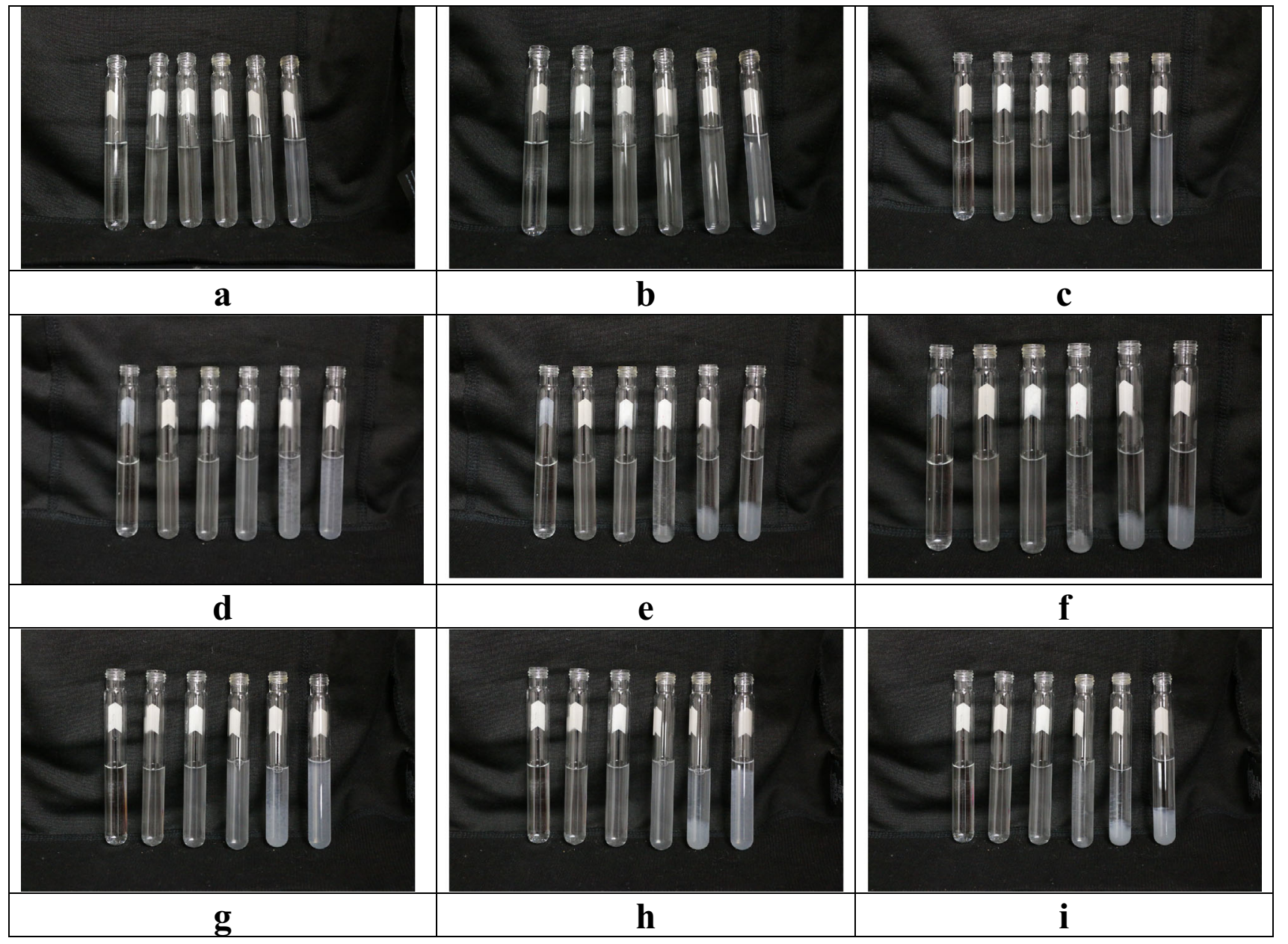

Images of nanofluids at $0 \mathrm{~min}(\mathrm{a}), 20 \mathrm{~min}$ (b), $30 \mathrm{~min}$ (c) after sonication of the set of nanofluids: From left to right are $0 \mathrm{wt} \%, 0.001 \mathrm{wt} \%, 0.005$ $\mathrm{wt} \%, 0.01 \mathrm{wt} \%, 0.05 \mathrm{wt} \%, 0.1 \mathrm{wt} \%$ nanoparticle suspensions with $5 \mathrm{wt} \%$ brine, respectively. Images of nanofluids at 0 min (d), $20 \mathrm{~min}$ (e), $30 \mathrm{~min}$ (f) after sonication of the set of nanofluids: From left to right are $0 \mathrm{wt} \%, 0.001 \mathrm{wt} \%, 0.005 \mathrm{wt} \%, 0.01 \mathrm{wt} \%, 0.05 \mathrm{wt} \%, 0.1 \mathrm{wt} \% \mathrm{nanofluids}$ with $5 \mathrm{wt} \%$ brine and $0.5 \mathrm{CMC}$ Tween ${ }^{\circledR} 20$, respectively. Images of nanofluids at $0 \mathrm{~min}(\mathrm{~g}), 20 \mathrm{~min}(\mathrm{~h}), 30 \mathrm{~min}$ (i) after sonication of the set of nanofluids: From left to right; $0 \mathrm{wt} \%, 0.001 \mathrm{wt} \%, 0.005 \mathrm{wt} \%, 0.01 \mathrm{wt} \%, 0.05 \mathrm{wt} \%, 0.1 \mathrm{wt} \%$ nanofluids with $5 \mathrm{wt} \%$ brine and $2 \mathrm{CMC}$ Tween ${ }^{\circledR} 20$, respectively

which kept decreasing IFT after the initial 30 min. Except for the $\mathrm{SiO}_{2} \mathrm{NP}$ concentrations at $0.005 \mathrm{wt} \%$ with $2 \mathrm{CMC}$ Tween ${ }^{\circledR} 20$ that yielded a minimal IFT at equilibrium, an increase in the $\mathrm{SiO}_{2} \mathrm{NP}$ concentrations in the brine-surfactant- $\mathrm{SiO}_{2}$ nanofluid-oil systems was observed with a corresponding increase in the IFT at equilibrium (Fig. 10). In the presence of surfactant, the maximum IFTs were obtained with the highest $\mathrm{SiO}_{2}$ NPs concentration $(0.1$ wt $\%$ ), while without surfactant, the maximum IFT was obtained without the addition of $\mathrm{SiO}_{2} \mathrm{NPs}$. Also, as the $\mathrm{SiO}_{2} \mathrm{NP}$ concentrations increased, the equilibrium IFT values with Tween ${ }^{\circledR} 20$ at $2 \mathrm{CMC}$ became larger than that obtained with Tween ${ }^{\circledR} 20$ at 0.5 CMC.

\section{Heavy crude oil}

The visual observation of the interface between brine-surfactant- $\mathrm{SiO}_{2} \mathrm{NPs}$ systems and drops of Lloydminster heavy crude oil are shown in Table 6. The IFT dynamics between the brine- $\mathrm{SiO}_{2} \mathrm{NP}$ systems and Lloydminster heavy crude is shown in Fig. 11a, and the processed data using a smoothing function based on the Loess Model in $\mathrm{R}$ is shown in Fig. 11b. A similar IFT trend was observed for all the $\mathrm{SiO}_{2} \mathrm{NP}$ concentrations. A variance in the IFTs between the $\mathrm{SiO}_{2}$ NP systems and the Lloydminster crude oil occurred over time with a sharp increase and a plateau as the IFT reaches equilibrium. These IFTs were also influenced by $\mathrm{SiO}_{2}$ NPs concentrations with initial IFT 


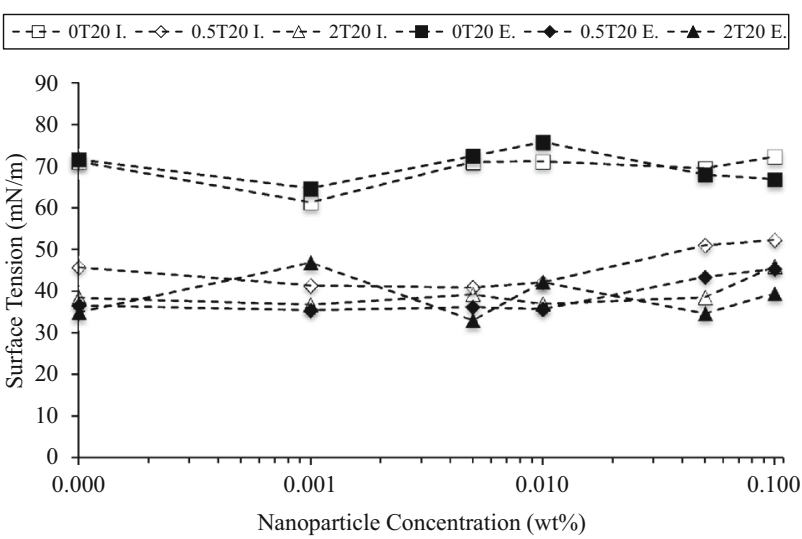

Fig. 6 Initial (I.) (open symbols) and equilibrium (E.) (solid symbols) behaviors of the surface tension for brine- $\mathrm{SiO}_{2}$ nanofluids with five different $\mathrm{SiO}_{2}$ nanoparticle concentrations (0.001 wt\% NP, $0.005 \mathrm{wt} \% \mathrm{NP}, 0.01 \mathrm{wt} \% \mathrm{NP}, 0.05 \mathrm{wt} \% \mathrm{NP}$, and $0.1 \mathrm{wt} \% \mathrm{NP})$ without Tween ${ }^{\circledR} 20$ (square symbols), in the presence of 0.5 CMC Tween ${ }^{\circledR} 20$ (diamond symbols), and in the presence of 2 CMC Tween ${ }^{\circledR} 20$ (triangle symbols)

values ranging from 4.30 to $16.29 \mathrm{mN} / \mathrm{m}$. An increase in the concentration of $\mathrm{SiO}_{2} \mathrm{NPs}$ resulted in a corresponding decrease in the IFT values of $\mathrm{SiO}_{2} \mathrm{NPs}$ at equilibrium, from $21.81 \mathrm{mN} / \mathrm{m}$ for $0.001 \mathrm{wt} \%$ to $14.19 \mathrm{mN} / \mathrm{m}$ for 0.1 wt $\%$. All of the $\mathrm{SiO}_{2}$ nanofluid systems showed an increase in the IFT dynamics over time. The reference equilibrium IFT obtained in the brine solution without $\mathrm{SiO}_{2} \mathrm{NPs}(0$ wt $\% \mathrm{SiO}_{2} \mathrm{NP}$ ) was $18.62 \mathrm{mN} / \mathrm{m}$.

The IFT dynamics between the brine-surfactant- $\mathrm{SiO}_{2}$ NP systems and Lloydminster crude oil in the presence of Tween ${ }^{\circledR} 20$ at $0.5 \mathrm{CMC}$ and $2 \mathrm{CMC}$ is shown in Fig. $11 \mathrm{c}$, e. The processed data developed from a smoothing function based on the Loess Model in R is shown in Fig. 11d, f. The IFT dynamics between the brine-surfactant- $\mathrm{SiO}_{2}$ NPs systems and the Lloydminster crude oil sample exhibited two separate values with the use of the Tween ${ }^{\circledR} 20$ at a 0.5 CMC: an initial IFT value range of 6.37 to $11.40 \mathrm{mN} / \mathrm{m}$, and $\mathrm{SiO}_{2} \mathrm{NP}$ concentrations of 0 to $0.001 \mathrm{wt} \%$. A sharp increase in the IFT was observed prior to the occurrence of a similar IFT equilibrium of approximately $11 \mathrm{mN} / \mathrm{m}$, which was the lowest obtained from the brine-surfactant$\mathrm{SiO}_{2} \mathrm{NPs}$ system. The remaining $\mathrm{SiO}_{2} \mathrm{NPs}$ concentrations $(0.005,0.01,0.05$, and $0.1 \mathrm{wt} \%)$ resulted in a sharp increase in the IFT to reach equilibrium. The highest equilibrium IFT values for brine-surfactant- $\mathrm{SiO}_{2} \mathrm{NPs}$ systems and the Lloydminster crude oil sample was $16.44 \mathrm{mN} / \mathrm{m}$ for Tween ${ }^{\circledR} 20$ at $0.5 \mathrm{CMC}$, which was obtained with $0.05 \mathrm{wt} \% \mathrm{SiO}_{2}$ NPs. For Tween ${ }^{\circledR} 20$ at 2

Table 4 Visual observation of the interface between brine-surfactant- $\mathrm{SiO}_{2} \mathrm{NPs}$ systems and drops of West Texas Intermediate light crude oil

\begin{tabular}{|c|c|c|c|c|c|c|}
\hline \multirow[t]{3}{*}{ Nanoparticle Concentrations } & \multicolumn{6}{|c|}{ Brine and Surfactant Concentrations } \\
\hline & \multicolumn{2}{|c|}{$5 \mathrm{wt} \%$ Brine } & \multicolumn{2}{|c|}{5 wt $\%$ Brine +0.5 CMC Tween ${ }^{B} 20$} & \multicolumn{2}{|c|}{$5 \mathrm{wt} \%$ Brine +2 CMC Tween ${ }^{(B)} 20$} \\
\hline & $1 \mathrm{~min}$ & $20 \mathrm{~min}$ & $1 \mathrm{~min}$ & $20 \mathrm{~min}$ & $1 \mathrm{~min}$ & $20 \mathrm{~min}$ \\
\hline $0 \mathrm{wt} \% \mathrm{SiO}_{2}$ & & & & & & \\
\hline $0.001 \mathrm{wt} \% \mathrm{SiO}_{2}$ & & & & & & \\
\hline $0.005 \mathrm{wt} \% \mathrm{SiO}_{2}$ & & & & & & \\
\hline $0.01 \mathrm{wt} \% \mathrm{SiO}_{2}$ & & & & & & \\
\hline $0.05 \mathrm{wt} \% \mathrm{SiO}_{2}$ & & & & & & \\
\hline $0.1 \mathrm{wt} \% \mathrm{SiO}_{2}$ & & & & & & \\
\hline
\end{tabular}

Representative drops images of West Texas Intermediate light crude oil at both the initial and equilibrium phases in brine-surfactant-SiO $\mathrm{NPS}_{2}$ systems 

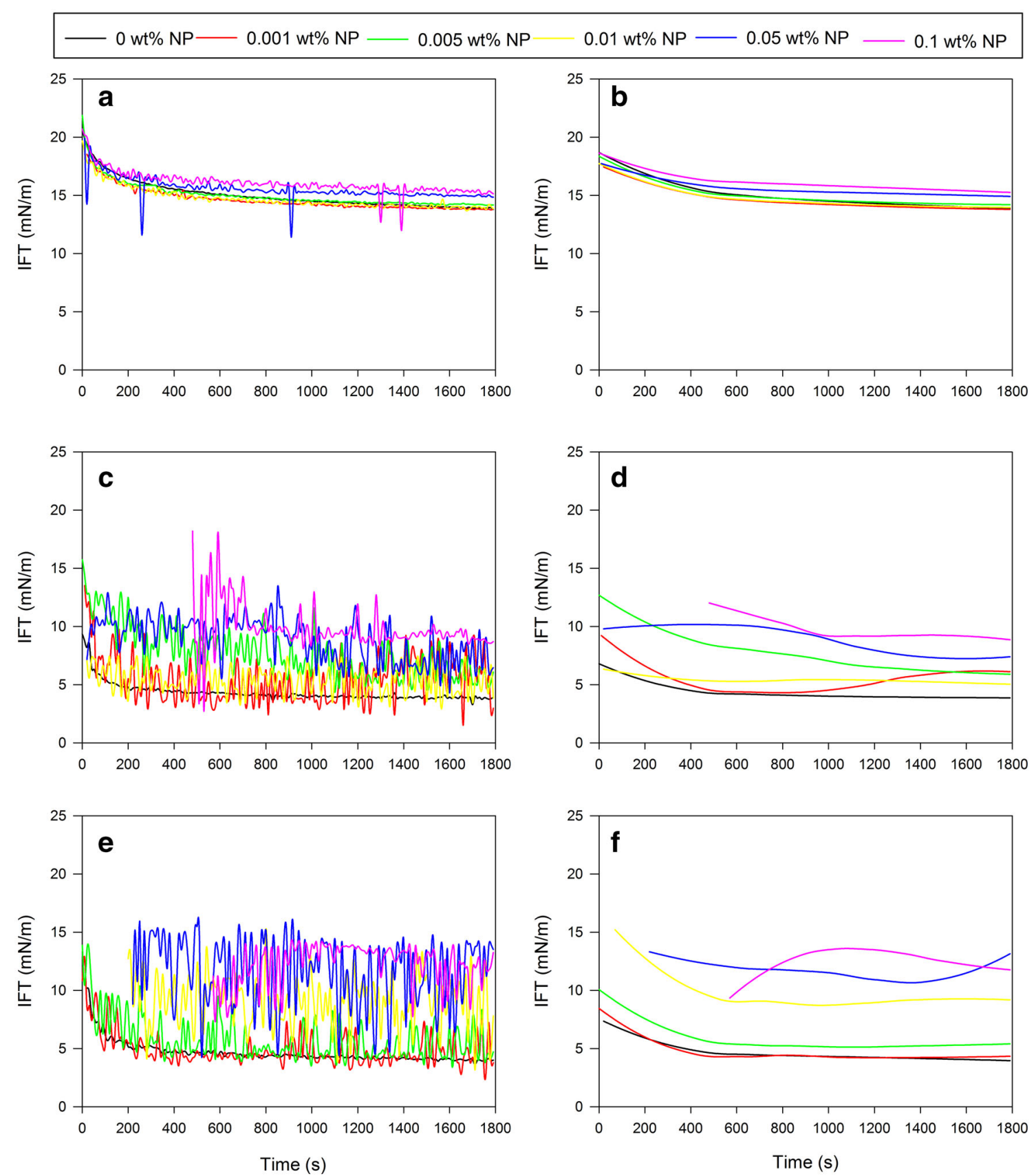

Fig. 7 Dynamic IFTs between brine-surfactant- $\mathrm{SiO}_{2}$ nanofluids and West Texas Intermediate light crude oil with different mass fractions of $\mathrm{SiO}_{2}$ nanoparticles $(0.001 \mathrm{wt} \% \mathrm{NP}, 0.005 \mathrm{wt} \% \mathrm{NP}, 0.01 \mathrm{wt} \% \mathrm{NP}$, $0.05 \mathrm{wt} \% \mathrm{NP}$, and $0.1 \mathrm{wt} \% \mathrm{NP})$ without Tween ${ }^{\circledR} 20$ (0 CMC): a raw

$\mathrm{CMC}$, the IFT dynamics between the brine-surfactant- $\mathrm{SiO}_{2}$ $\mathrm{NP}$ systems and the Lloydminster crude oil showed an oscillating change in IFT with time. Initial IFT values fell within a range of 7.15 to $18.79 \mathrm{mN} / \mathrm{m}$, with the highest IFT equilibrium achieved at $19.55 \mathrm{mN} / \mathrm{m}$ obtained with 0.1 wt $\% \mathrm{SiO}_{2} \mathrm{NPs}$, and the lowest at 8.70 with $0.001 \mathrm{wt} \%$.

As shown in Fig. 12, the equilibrium IFTs of the brine$\mathrm{SiO}_{2}$ nanofluid oil systems are higher than those produced

data, and $\mathbf{b}$ processed data in Loess Model in R; in the presence of 0.5 CMC Tween ${ }^{\circledR}$ 20: $\mathbf{c}$ raw data, and $\mathbf{d}$ processed data in Loess Model in $\mathrm{R}$; and in the presence of $2 \mathrm{CMC}$ Tween ${ }^{\circledR} 20$ : e raw data, and f processed data in the Loess Model in $\mathrm{R}$

with the surfactant, except for the highest concentrations of $\mathrm{SiO}_{2} \mathrm{NPs}$. Also, an increase in the $\mathrm{SiO}_{2} \mathrm{NP}$ concentration generally resulted in a corresponding increase of the equilibrium of the IFT brine-surfactant- $\mathrm{SiO}_{2}$ nanofluid-oil systems, while a decrease of equilibrium IFT was generally observed with the brine- $\mathrm{SiO}_{2}$ nanofluid-oil systems. 


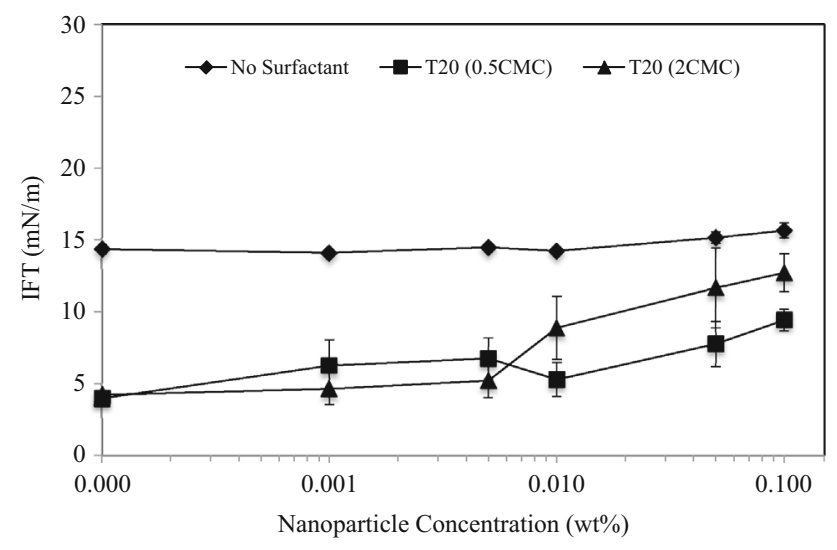

Fig. 8 Equilibrium IFTs between brine- $\mathrm{SiO}_{2}$ nanofluids and West Texas Intermediate light crude oil with different mass fractions of $\mathrm{SiO}_{2}$ nanoparticles (0.001 wt \% NP, $0.005 \mathrm{wt} \% \mathrm{NP}, 0.01 \mathrm{wt} \% \mathrm{NP}$, $0.05 \mathrm{wt} \% \mathrm{NP}$, and $0.1 \mathrm{wt} \% \mathrm{NP}$ ) without surfactant (diamond symbols) in the presence of 0.5 CMC Tween ${ }^{\circledR} 20$ (square symbols) and 2 CMC Tween ${ }^{\circledR} 20$ (triangle symbols)

\section{Discussion}

\section{Stability of $\mathrm{SiO}_{2}$ based nanofluids}

The stability of nanofluids is defined by the extent to which $\mathrm{SiO}_{2} \mathrm{NPs}$ remain in suspension over time. The stability of our nanofluid suspensions was examined via the analyses of size, zeta potential, and sedimentation rates of $\mathrm{SiO}_{2} \mathrm{NPs}$. The high surface free energy of $\mathrm{SiO}_{2} \mathrm{NPs}$ often causes the formation of large nanoaggregates that cannot remain in suspension (Ganguly and Chakraborty 2011). When the $\mathrm{SiO}_{2}$ NPs leave suspension, they cannot connect at the liquid-liquid interface and alter the IFT. The size of the $\mathrm{SiO}_{2}$ nanoaggregates establishes the possibility of settling due to the aggregation phenomenon, leaving smaller stable nanoaggregates the possibility of affecting the IFT. In $\mathrm{SiO}_{2} \mathrm{NPs}$ concentrations of 0.001 and $0.1 \mathrm{wt} \%$, the $\mathrm{SiO}_{2}$ NPs aggregated to $1503 \pm 289$ and $249 \pm 12 \mathrm{~nm}$ diameter particles, respectively, in a $5 \%$ brine solution. An increasing concentration of NPs in brine reduced the size of nanoaggregates, due to the settling of the larger nanoaggregates formed at higher concentrations of NPs, thus leaving the smaller nanoaggregates in suspension. The addition of $0.5 \mathrm{CMC}$ of surfactant increased the $\mathrm{SiO}_{2}$ nanoaggregate diameters to $1593 \pm 282$ and $2951 \pm 1033 \mathrm{~nm}$ at 0.001 and $0.1 \mathrm{wt} \%$ concentrations respectively. The addition of surfactant was added to the systems at $2 \mathrm{CMC}$ increased the nanoaggregate diameters to $1680 \pm 648$ and $3475 \pm 1099 \mathrm{~nm}$ at concentrations of 0.001 and $0.1 \mathrm{wt} \%$ respectively. In these suspensions, higher $\mathrm{SiO}_{2}$ NPs concentrations produced nanoparticle-

Table 5 Visual observation of the interface between brine-surfactant- $\mathrm{SiO}_{2} \mathrm{NPs}$ systems and drops of Prudhoe Bay medium crude oil

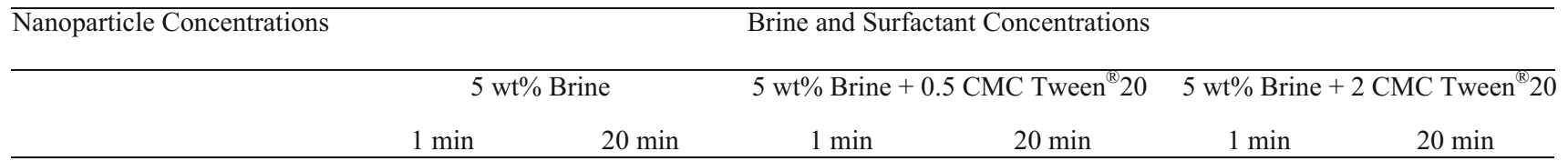

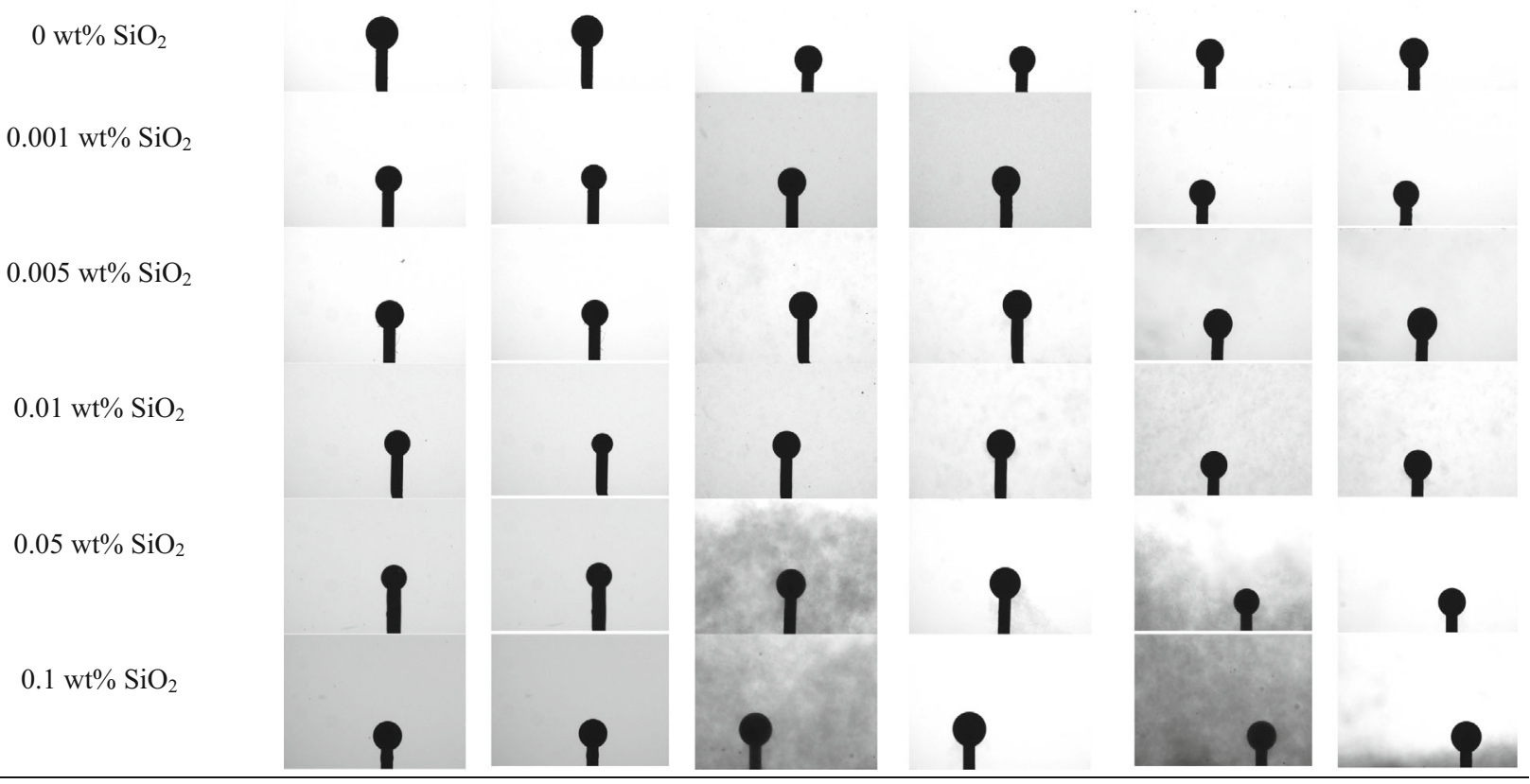

Representative drop images of Prudhoe Bay medium crude oil at initial and equilibrium phases in brine-surfactant-SiO $\mathrm{NPs}_{2}$ systems

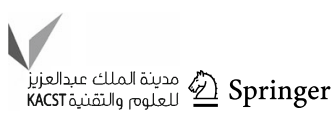



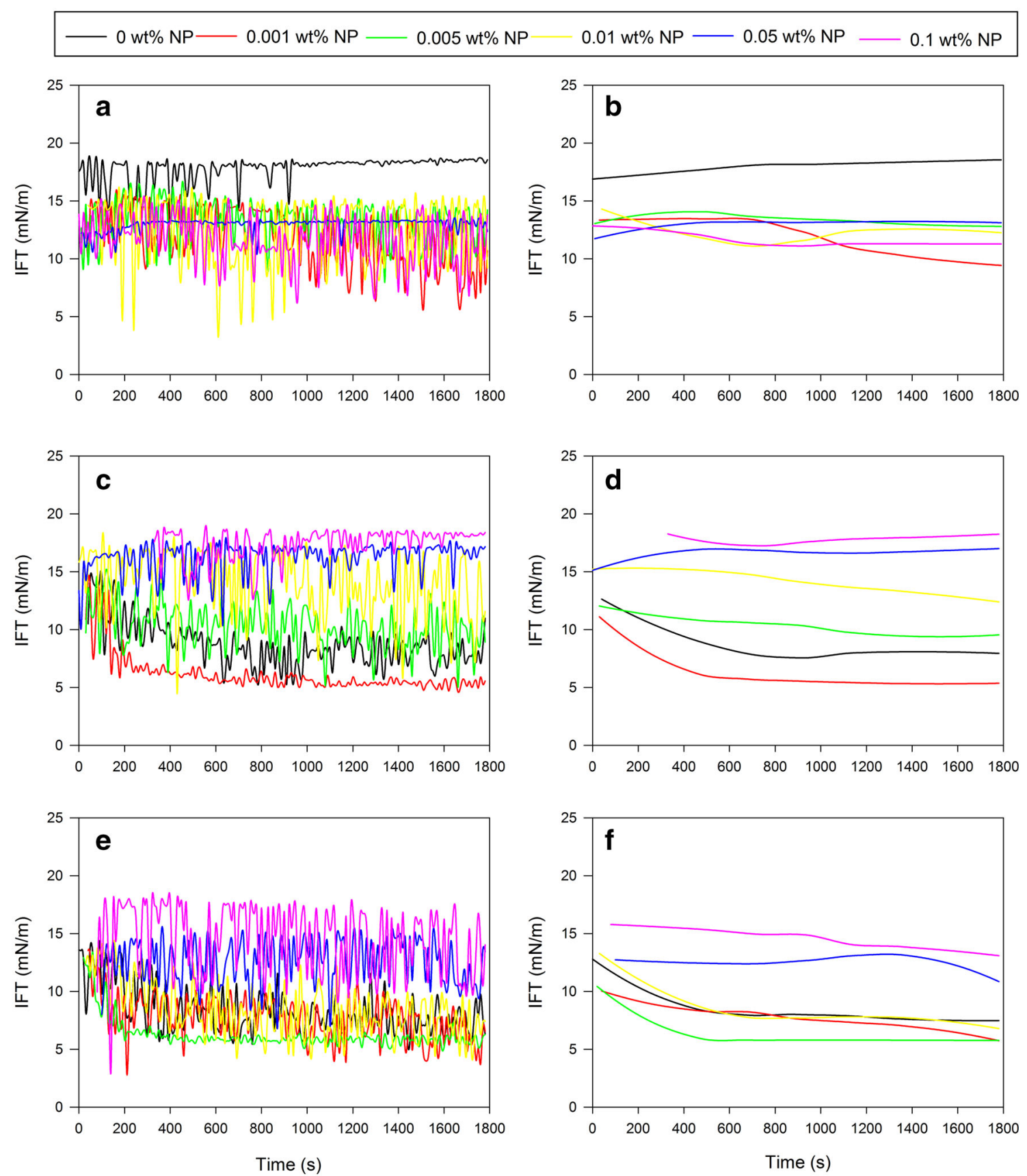

Fig. 9 Dynamic IFTs between brine-surfactant-SiO $\mathrm{S}_{2}$ nanofluids and Prudhoe Bay medium crude oil with different mass fractions of $\mathrm{SiO}_{2}$ nanoparticles (0.001 wt\% NP, $0.005 \mathrm{wt} \% \mathrm{NP}, 0.01 \mathrm{wt} \% \mathrm{NP}, 0.05$ wt $\%$ NP, and $0.1 \mathrm{wt} \% \mathrm{NP})$ without Tween ${ }^{\circledR} 20$ (0 CMC): a raw data,

surfactant complexes and removed the surfactant from the bulk solution. The surfactant in turn affected the interactions between the nanoparticles by increasing repulsion forces between the $\mathrm{SiO}_{2}$ NPs. The lack of surfactant at higher $\mathrm{SiO}_{2} \mathrm{NPs}$ concentrations indicates that the $\mathrm{SiO}_{2} \mathrm{NPs}$ produced larger $\mathrm{SiO}_{2}$ nanoaggregates with larger-thansuitable diameters (Cieslinski and Krygier 2014; Ehtesabi et al. 2014). The smaller diameters of nanoaggregates

and $\mathbf{b}$ processed data in Loess Model in $\mathrm{R}$; in the presence of 0.5 CMC Tween ${ }^{\circledR} 20$ : $\mathbf{c}$ raw data, and $\mathbf{d}$ processed data in Loess Model in $\mathrm{R}$; and in the presence of $2 \mathrm{CMC}$ Tween ${ }^{\circledR} 20$ : e raw data, and f processed data in the Loess Model in $\mathrm{R}$

reported in previous findings were most likely the consequence of longer sonication times which yielded a more thorough mixture of the NPs into the suspension. Furthermore, unlike similar studies detailing various nanoaggregates, we used a higher concentration of $5 \%$ brine to generate higher aggregation rates and larger nanoaggregate sizes (Ehtesabi et al. 2014; Hendraningrat and Torsæter 2014). This variance in brine characteristics may serve as a 


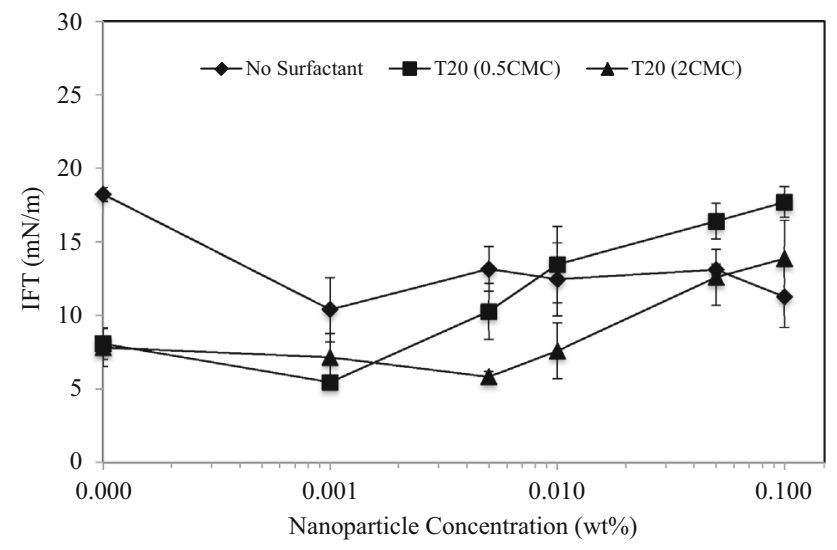

Fig. 10 Equilibrium IFTs between brine- $\mathrm{SiO}_{2}$ nanofluids and Prudhoe Bay medium crude oil with different mass fractions of $\mathrm{SiO}_{2}$ nanoparticles $(0.001 \mathrm{wt} \% \mathrm{NP}, 0.005 \mathrm{wt} \% \mathrm{NP}, 0.01 \mathrm{wt} \% \mathrm{NP}, 0.05$ $\mathrm{wt} \% \mathrm{NP}$, and $0.1 \mathrm{wt} \% \mathrm{NP}$ ) without surfactant (diamond symbols) in the presence of $0.5 \mathrm{CMC}$ Tween ${ }^{\circledR} 20$ (square symbols) and $2 \mathrm{CMC}$ Tween ${ }^{\circledR} 20$ (triangle symbols)

possible explanation for the larger size of nanoaggregates detected in our study in which the large standard deviations observed for the nanoaggregate size indicate a high degree of polydispersity of the nanofluids. However, further research should be conducted in the development of smaller nanoaggregates for purposes of increasing the stability of the brine-surfactant- $\mathrm{SiO}_{2}$ nanofluid systems and ensure the optimum migration of $\mathrm{SiO}_{2} \mathrm{NPs}$ and surfactant to the oil-aqueous interface for a maximum potential impact on IFT.

The influence of the $\mathrm{SiO}_{2}$ NPs size distribution on the stability of $\mathrm{SiO}_{2} \mathrm{NPs}$ was revealed. In the brine- $\mathrm{SiO}_{2} \mathrm{NP}$ systems, the lower $\mathrm{SiO}_{2} \mathrm{NP}$ concentrations of 0.001 and $0.005 \mathrm{wt} \%$ showed a polydisperse size distribution and resulted in the formation of larger $\mathrm{SiO}_{2} \mathrm{NP}$ aggregates than higher concentration of $\mathrm{SiO}_{2} \mathrm{NPs}$ that tended to be monodispersed. In the brine-Tween ${ }^{\circledR} 20-\mathrm{SiO}_{2} \mathrm{NP}$ systems, the lower $\mathrm{SiO}_{2} \mathrm{NP}$ concentrations of 0.001 and $0.005 \mathrm{wt} \%$ generated the smallest sizes of $\mathrm{SiO}_{2} \mathrm{NP}$ aggregates. This may be attributed to the combining effects of the polydisperse size distribution of $\mathrm{SiO}_{2} \mathrm{NPs}$ and the surfactant that limits the aggregation phenomena.

The zeta potential values observed for the majority of the nanofluid systems were close to zero, an indication of the low degree of stability of the systems, a stability that can be increased by the addition of a surfactant (Fig. 2a, b, c) (Zargartalebi et al. 2014). The adsorption of surfactants onto nanoparticles eventually triggers a steric repulsion on the $\mathrm{SiO}_{2} \mathrm{NPs}$, which in conjunction with the electrostatic forces of the $\mathrm{SiO}_{2}$ NPs promotes suspension stability. The larger size of $\mathrm{SiO}_{2}$ nanoaggregates measured with the

Table 6 Visual observation of the interface between brine-surfactant-SiO 2 NPs systems and drops of Lloydminster heavy crude oil

\begin{tabular}{|c|c|c|c|c|c|c|}
\hline \multirow[t]{3}{*}{ Nanoparticle Concentrations } & \multicolumn{6}{|c|}{ Brine and Surfactant Concentrations } \\
\hline & \multicolumn{2}{|c|}{$5 \mathrm{wt} \%$ Brine } & \multicolumn{2}{|c|}{$5 \mathrm{wt} \%$ Brine +0.5 CMC Tween ${ }^{\circledR} 20$} & \multicolumn{2}{|c|}{$5 \mathrm{wt} \%$ Brine +2 CMC Tween ${ }^{\circledR} 20$} \\
\hline & $1 \mathrm{~min}$ & $20 \mathrm{~min}$ & $1 \mathrm{~min}$ & $20 \mathrm{~min}$ & $1 \mathrm{~min}$ & $20 \mathrm{~min}$ \\
\hline $0 \mathrm{wt} \% \mathrm{SiO}_{2}$ & & & & & & \\
\hline $0.001 \mathrm{wt} \% \mathrm{SiO}_{2}$ & & & & & & \\
\hline $0.005 \mathrm{wt} \% \mathrm{SiO}_{2}$ & & & & & & \\
\hline $0.01 \mathrm{wt} \% \mathrm{SiO}_{2}$ & & & & & & \\
\hline $0.05 \mathrm{wt} \% \mathrm{SiO}_{2}$ & & & & & & \\
\hline $0.1 \mathrm{wt} \% \mathrm{SiO}_{2}$ & & & & & & \\
\hline
\end{tabular}

Representative drop images of Lloydminster heavy crude oil at initial and equilibrium phases in brine-surfactant-SiO $\mathrm{NPs}_{2}$ systems

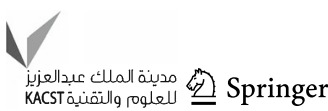



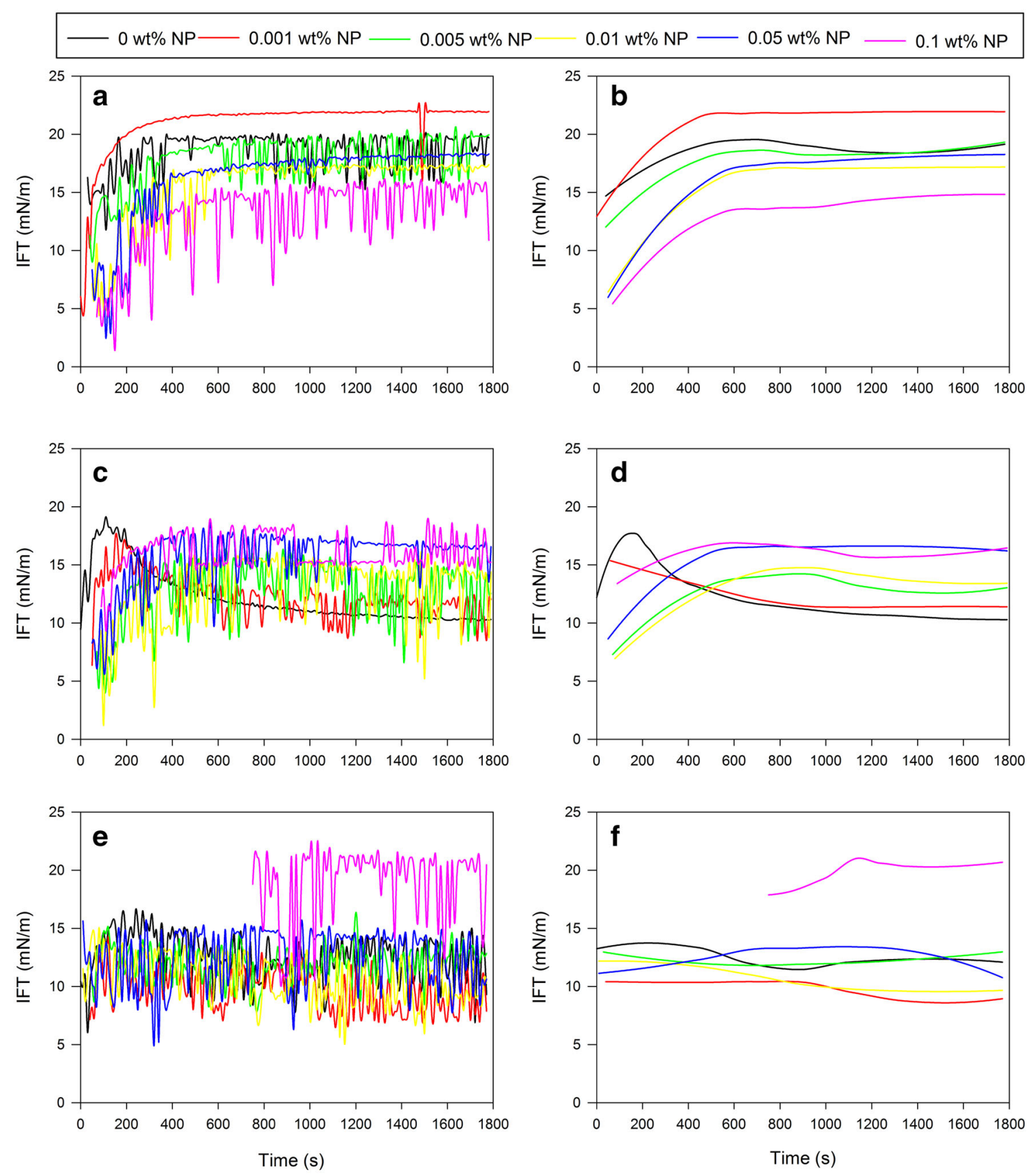

Fig. 11 Dynamic IFTs between brine-surfactant- $\mathrm{SiO}_{2}$ nanofluids and Lloydminster heavy crude oil with different mass fractions of $\mathrm{SiO}_{2}$ nanoparticles $(0.001 \mathrm{wt} \% \mathrm{NP}, 0.005 \mathrm{wt} \% \mathrm{NP}, 0.01 \mathrm{wt} \% \mathrm{NP}, 0.05$ wt $\% \mathrm{NP}$, and $0.1 \mathrm{wt} \% \mathrm{NP})$ without Tween ${ }^{\circledR} 20$ (0 CMC): a raw data,

addition of the nonionic surfactant, Tween ${ }^{\circledR} 20$, indicated the creation of these surfactant-nanoparticle complexes that remained in suspension. The largest zeta potential among the systems was $-11 \pm 38 \mathrm{mV}$ in a brine with $0.001 \mathrm{wt} \%$ NPs, whereas the corresponding zeta potential for the identical system with a surfactant was only $9 \pm 32 \mathrm{mV}$ at $0.5 \mathrm{CMC}$ and $6 \pm 41 \mathrm{mV}$ at $2 \mathrm{CMC}$. The relatively large standard deviation between measurements derived mostly

and $\mathbf{b}$ processed data in Loess Model in $\mathrm{R}$; in the presence of 0.5 CMC Tween ${ }^{\circledR} 20$ : $\mathbf{c}$ raw data, and $\mathbf{d}$ processed data in Loess Model in $\mathrm{R}$; and in the presence of $2 \mathrm{CMC}$ Tween ${ }^{\circledR} 20$ : e raw data, and f processed data in the Loess Model in $\mathrm{R}$

from the positive and negative measurements recorded for the samples.

As observed in our study, the sedimentation rate of the nanofluid systems strongly supports the previously established association of the nanoaggregate size with that of the sedimentation rate (Cieslinski and Krygier 2014). In our study, a settling of the NPs from the solutions to almost half their initial concentration was observed after a $30 \mathrm{~min}$ 


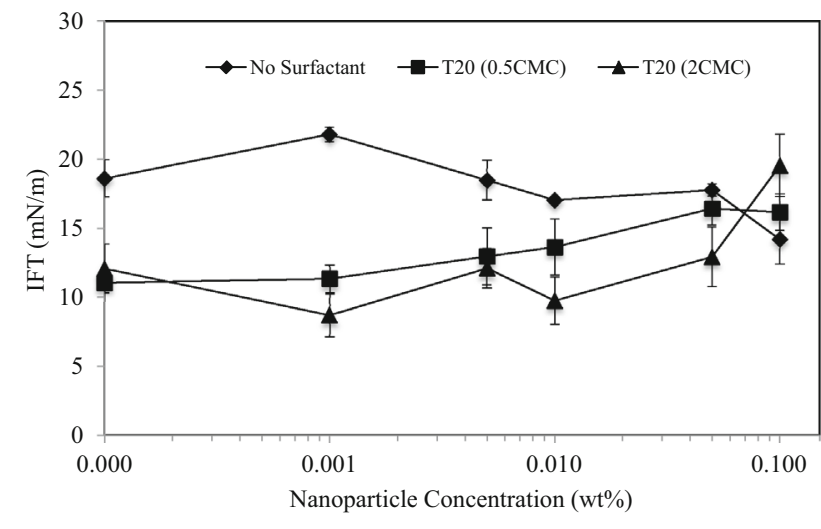

Fig. 12 Equilibrium IFTs between brine- $\mathrm{SiO}_{2}$ nanofluids and Lloydminster heavy crude oil with different mass fractions of $\mathrm{SiO}_{2}$ nanoparticles (0.001 wt\% NP, $0.005 \mathrm{wt} \% \mathrm{NP}, 0.01 \mathrm{wt} \% \mathrm{NP}, 0.05$ wt $\% \mathrm{NP}$, and $0.1 \mathrm{wt} \% \mathrm{NP}$ ) without surfactant (diamond symbols) in the presence of $0.5 \mathrm{CMC}$ Tween ${ }^{\circledR} 20$ (square symbols) and $2 \mathrm{CMC}$ Tween ${ }^{\circledR} 20$ (triangle symbols)

period. The lowest sedimentation proportion occurred within a NP brine solution of $0.001 \mathrm{wt} \%$ with a lower relative concentration of $0.53 \pm 0.01$, a behavior that reflected the size of the nanoaggregates in a $0.001 \mathrm{wt} \%$ solution. The larger size of these nanoaggregates was due to the lack of settling that is so characteristic in low $\mathrm{SiO}_{2}$ NP concentrations. The opposite behavior, however, remained valid for the brine and surfactant system as the nanoparticle-surfactant complexes retain the nanoaggregates in suspension, even with an increase in the nanoaggregate size.

\section{Raspberry-like morphology of $\mathrm{SiO}_{2}$ nanoparticles}

SEM confirms the raspberry-like morphology particles of these assemblages of $\mathrm{SiO}_{2}$ nanoparticles (Fig. 4). The roughness of the coating provided by the raspberry-like morphology particles is critical for the wetting properties of these $\mathrm{SiO}_{2}$ nanofluid systems (Carcouet 2014; Carcouet et al. 2014; Fan et al. 2012; Yu et al. 2017; Zanini et al. 2017). The formation of these raspberry-like particles in brine- $\mathrm{SiO}_{2} \mathrm{NP}$ systems, with high surface area, may be attributed to the aggregation and self-assembly capabilities of $\mathrm{SiO}_{2} \mathrm{NPs}$ induced by the salt concentration (i.e., $5 \mathrm{wt} \%$ $\mathrm{NaCl}$ ) (Uzelac et al. 2017). The coupling of the physicochemical properties of the $\mathrm{SiO}_{2}$ nanoparticles and Tween ${ }^{\circledR} 20$ surfactant have proven to be very effective in altering the interfacial process in oil- $\mathrm{SiO}_{2}$ nanofluid systems (i.e., the decrease of the interfacial tension of oil- $\mathrm{SiO}_{2}$ nanofluid systems) under synergistic effects of $\mathrm{SiO}_{2} \mathrm{NP}$ and surfactant concentrations and as a function of the crude oil properties. SEM images of the hybrid particles of Tween ${ }^{\circledR} 20 / \mathrm{SiO}_{2}$ confirm that the raspberry-like morphology was gained directly from the polymerization of the
$\mathrm{SiO}_{2}$-stabilized nanoparticles. Similar raspberry-like morphology nanostructures have been previously also reported with metalloid nanoparticles (e.g., silicon dioxide nanoparticles) and metal nanoparticles (e.g., iron oxide nanoparticles) (Hu et al. 2016b; Kresge et al. 1992; Roosz et al. 2017; Stauch et al. 2017; Uzelac et al. 2017; Zanini et al. 2017; Zhao and Middelberg 2013). The effects of surfactant and salt electrolyte on the morphology of the self-assembled particles (brine- $\mathrm{SiO}_{2} \mathrm{NP}$ systems) and selfassembled polymer composites were also visualized. It has been previously demonstrated that the coverage of the raspberry-like particle increases with increasing salt concentration (Meeusen 2017). Our results support these findings as a high coverage of the raspberry-like particles was observed with a high $\mathrm{NaCl}$-based brine concentration of $5 \mathrm{wt} \%$ for the $\mathrm{Tween}^{\circledR} 20-\mathrm{SiO}_{2} \mathrm{NP}$ systems. The development of this raspberry-like particles material with high surface area, high salt stability, and high capability of interfaces alteration and therefore wettability changes offers a wide range of applications in the fields of applied nanoscience, environmental engineering, and petroleum engineering.

\section{Effects of $\mathrm{SiO}_{2}$ nanoparticles concentration and surfactant concentration on the dynamic and equilibrium interfacial tension at the oil- aqueous interface for brine-surfactant-SiO ${ }_{2}$ nanofluid-oil systems}

Altering the IFT at the oil-aqueous interface in a reservoir is necessary for generating the mobility and recovery of both the oil that is trapped within the small pores of the geologic formations and the residual oil that remains within the pores after the secondary recovery phase (Roustaei and Bagherzadeh 2013, 2015; Joonaki and Ghanaatian 2014; Yuan et al. 2015; Hu et al. 2016a; Pu et al. 2016). The wettability of an oil reservoir is dependent on the conditions that exist at the pore interfaces, conditions which govern the stability and movement of the interfaces and the resulting oil migration. In traditional reservoir exploitation under original wetting conditions, i.e. water-wet conditions before any oil migration, the decrease of IFT will induce a decrease in capillary pressure in the pores which results in the mobilization of both the trapped and residual oil. With an extreme change in wettability such as in the wettability reversal of a reservoir to a water-wet condition, a central process of EOR, an increase in IFT will lead to increasing capillary pressures that will result in an increased wettability of the pores, and a strong imbibition of the wetting phase into the small pores which will thus enhance the oil recovery (Yu et al. 2008). In our study on the effects of $\mathrm{SiO}_{2}$ nanoparticles on IFT of brine-surfactant-crude oil systems, we determined that these nanoparticles either 
decrease IFT, increase IFT, or exhibit no affect at all. Clearly, the constituents of these oil and aqueous substances do indeed affect the IFT behavior of brine-surfactant-crude oil systems, with the presence of nanoparticles leading to these contrasting IFT trends according to the type of crude oil.

Our study also demonstrates the effect of $\mathrm{SiO}_{2} \mathrm{NPs}$ on interfaces in crude oil-surfactant-brine systems with diverse behaviors at these interfaces that were dependent on the physico-chemical of the oil, and the concentrations of both NPs and surfactants. Changes in the oil-aqueous phase IFT were observed in the presence of nonionic surfactant as a result of adding $\mathrm{SiO}_{2} \mathrm{NPs}$ to the aqueous phase, as also observed by Eskandar et al. (2007) and Wang et al. (2004). For most oils, in the absence of nonionic surfactant, no significant change in oil-water IFT was detected with the addition of approximately $0.1 \mathrm{wt} \%$ of $\mathrm{SiO}_{2} \mathrm{NPs}$. In the presence of 0.5 and 2 CMC Tween ${ }^{\circledR} 20$, the IFT of the different systems either increased or decreased as a function of the concentration of $\mathrm{SiO}_{2}$ NPs. In terms of the IFT trends, however, a threshold concentration of $\mathrm{SiO}_{2} \mathrm{NPs}$ was observed for the medium ( 0.5 and $2 \mathrm{CMC}$ ) and heavy (2 CMC) oil systems. Concentrations above and below this $\mathrm{SiO}_{2}$ NPs threshold concentration resulted in a respective increase and decrease, with the latter caused by the spontaneous self-assembly of surfactant or $\mathrm{SiO}_{2} \mathrm{NPs}$ at liquidliquid interfaces, which are a central component in EOR (Biswal and Singh 2016). A further increase in concentration also greatly increased the IFT values to levels much greater than detected in the absence of NPs. For medium and heavy crude oil, the presence of $\mathrm{SiO}_{2} \mathrm{NPs}$ enhances the efficiency of nonionic surfactant molecules in decreasing the IFT. It has been established that the presence of $\mathrm{SiO}_{2}$ $\mathrm{NPs}$ at the interfacial layer does cause a reduction of IFT. Specifically, at low concentrations, $\mathrm{SiO}_{2} \mathrm{NPs}$ attach to the liquid surface with a subsequent decrease in surface tension from adsorption (Suleimanov et al. 2011). However, at concentrations larger than $0.001 \mathrm{wt} \%, \mathrm{SiO}_{2} \mathrm{NPs}$ remove the surfactant from the bulk aqueous phase, which in turn decreases the free surfactant. This phenomenon increases as the concentration of $\mathrm{SiO}_{2}$ NPs increases, with the ultimate removal of nearly the entirety of the surfactant from the bulk phase with no free surfactant remaining in the bulk solution. The depletion of the surfactant due to adsorption on particle surfaces may also cause the increase in the oilwater IFT (Brian and Chen 1987). As shown in Figs. 10 and 12, IFTs are close to the brine system IFTs for nanoparticle concentrations larger than $0.05 \mathrm{wt} \%$, indicating that the $\mathrm{SiO}_{2} \mathrm{NPs}$ remove the surfactant from the bulk aqueous solution, as supported by sedimentation and visual observations (Fig. 2b, c, and Table 3). Also, for $\mathrm{SiO}_{2} \mathrm{NPs}$ below $0.005 \mathrm{wt} \%$, the IFT is controlled by a mixed layer composed of attached $\mathrm{SiO}_{2}$ NPs and surfactant adsorbed at liquid interfaces. No free surfactant remains above this concentration with the increase in IFT possibly attributed to the attachment of $\mathrm{SiO}_{2} \mathrm{NPs}$ at the interface.

The IFT of oil-aqueous systems shifts to high IFT values after the $\mathrm{SiO}_{2} \mathrm{NP}$ concentration reaches a threshold and increases as a function of $\mathrm{SiO}_{2}$ NPs. In most systems, the addition of $\mathrm{SiO}_{2}$ NPs to a surfactant in concentrations higher than a single CMC causes an increase in the IFT after the $\mathrm{SiO}_{2} \mathrm{NP}$ threshold concentration is reached. The equilibrium IFT of the surfactant may be affected by the adsorption of the surfactant on the particles, the depletion of the free surfactant from the interface, and the interfacial transfer of particles as surfactant carriers (Gonzenbach et al. 2006). The attachment of $\mathrm{SiO}_{2} \mathrm{NPs}$ at the oil-water interface, if their concentration is low, need not automatically indicate a significant change in IFT, however. Nonetheless, from this point, Tween ${ }^{\circledR} 20$ molecules adsorbed on $\mathrm{SiO}_{2} \mathrm{NPs}$ do transfer into the liquid-liquid interface. This transfer process, which can govern the decrease in IFTs, is more complex with increases in particle concentration at the oil-water interface. Either an increase or a decrease in slope above certain concentrations of $\mathrm{SiO}_{2} \mathrm{NPs}$ for dynamic IFTs indicates the beginning of a possible interaction of $\mathrm{SiO}_{2} \mathrm{NPs}$ above a certain level of coverage of the surface. In this case, particle-particle interactions can become essential and have a greater influence on IFT (e.g., increase nanoaggregate size).

Furthermore, an increase in surfactant concentration in medium and heavy oil reduces the efficacy of the $\mathrm{SiO}_{2} \mathrm{NPs}$ in that enough nonionic surfactant molecules are at the interface to maintain IFT at higher levels. In the case of nonionic surfactants, as more Tween ${ }^{\circledR} 20$ molecules migrate from the bulk phase to the interface, more surfactant molecules remain free at a higher rather than a lower CMC for the same $\mathrm{SiO}_{2} \mathrm{NP}$ concentration. Consequently, the IFT decreases until the NP concentrations reach a threshold, at which point the synergetic effects manifest as opposite of the antagonistic effects (Ranatunga et al. 2011; Moghadam and Azizian 2014a, b, c; Moghadam et al. 2015; Biswal and Singh 2016). Below this threshold, a synergistic effect is observed between the nonionic surfactants and $\mathrm{SiO}_{2}$ NPs which decreases the IFT within the oil-water interfaces. The adsorption of both the $\mathrm{SiO}_{2} \mathrm{NPs}$ and surfactants at the individual interface also increases the IFT reduction from this synergistic effect. For $\mathrm{SiO}_{2}$ NPs below a threshold concentration (Figs. 10 and 12), the synergistic interactions between NPs and surfactant decrease the IFT beyond that observed for individual components. Therefore, for low concentrations of $\mathrm{SiO}_{2}$ $\mathrm{NPs}$, the IFT is governed by a mixed layer comprised of attached $\mathrm{SiO}_{2} \mathrm{NPs}$ and the surfactant adsorbed to the liquid interface (Ravera et al. 2006, 2008; Suleimanov et al. 2011). Conversely, an antagonistic effect is detected above 
this threshold level within an increase of the IFT at the oilwater interface. This synergistic/antagonistic effect is a function of the oil properties, the surfactant properties and concentrations, and the nanoparticle concentration. The concentration of $\mathrm{SiO}_{2}$ NPs controls either the increase or decrease in IFTs, which either increases or reduces the surfactant from an oil-water interface, while the attachment energy of $\mathrm{SiO}_{2} \mathrm{NPs}$ is predominantly controlled by the charge and concentration of the surfactant.

The increase in the concentration of the surfactant, which results in a corresponding increase in the surface coverage of $\mathrm{SiO}_{2} \mathrm{NPs}$, also causes an increase in the attraction of $\mathrm{SiO}_{2}$ NPs to the interface of the oil-aqueous systems (Ravera et al. 2006, 2008; Zargartalebi et al. 2014). The $\mathrm{SiO}_{2}$ NPs that are surrounded by large amounts of surfactant act as a carrier of the nonionic surfactant Tween ${ }^{\circledR} 20$ which migrates toward the interface of the oilaqueous systems. Consequently, the reduction in IFT is the possible result of a surfactant release from the particles at the interface and an alteration in tension (Ahualli et al. 2011). Further, the precipitous decline in the dynamic IFT may be a result of the physical properties of $\mathrm{SiO}_{2}$ NPs (e.g., the size) rather than the interaction between $\mathrm{SiO}_{2}$ NPs and surfactant. A reduction in IFT may be caused by the attachment of $\mathrm{SiO}_{2}$ NPs at the oil-aqueous interface. The hydrophobic and hydrophilic nature of the $\mathrm{SiO}_{2}$ NPs causes a manifestation of this attachment (Ghezzi et al. 2001; Schwartz et al. 2001).

The influence of the $\mathrm{SiO}_{2}$ NPs size distribution on the IFTs was detected for low $\mathrm{SiO}_{2} \mathrm{NP}$ concentrations. For $\mathrm{SiO}_{2} \mathrm{NP}$ concentrations of 0.001 and $0.005 \mathrm{wt} \%$, larger sizes of $\mathrm{SiO}_{2} \mathrm{NP}$ aggregates and polydisperse size distributions of $\mathrm{SiO}_{2}$ NPs were observed for the brine-SiO${ }_{2} \mathrm{NP}$ systems. These systems induced a decrease in IFTs in the case of the medium crude oil Prudhoe Bay. For $\mathrm{SiO}_{2} \mathrm{NP}$ concentrations ranging from 0.001 to $0.01 \mathrm{wt} \%$, smaller sizes of $\mathrm{SiO}_{2} \mathrm{NP}$ aggregates were formed and polydisperse size distributions of $\mathrm{SiO}_{2}$ NPs were also observed for the brine-0.5 CMC Tween ${ }^{\circledR} 20-\mathrm{SiO}_{2} \mathrm{NP}$ and the brine-2 CMC Tween ${ }^{\circledR} 20-\mathrm{SiO}_{2} \mathrm{NP}$ systems. In the case of the medium crude oil Prudhoe Bay, these two systems also induced a decrease in IFTs, while for the heavy oil Lloydminster the largest decrease in IFT was generated by the $2 \mathrm{CMC}$ Tween ${ }^{\circledR} 20-0.001 \% \mathrm{SiO}_{2}$ NPs system.

\section{Effects of $\mathrm{SiO}_{2}$ nanoparticles on nonionic surfactant properties: interfacial and adsorption mechanisms}

The interfacial behavior of nonionic surfactant in the presence of $\mathrm{SiO}_{2}$ NPs can provide some insights concerning their interfacial and adsorption mechanisms. It is possible that the observed IFTs are a result of either (1) the depletion of surfactant solution from the adsorption of
Tween ${ }^{\circledR} 20$ on the particle, which thus causes an increase in IFT with an increase in nanoparticle concentration, or (2) the adsorption of NPs at the interfacial layer, which decreases the IFT (Ravera et al. 2006, 2008). In the absence of surfactant or at low surfactant concentrations, $\mathrm{SiO}_{2}$ NPs are fully wetted in the aqueous phase and remain within the bulk solution, avoiding the interface (Ravera et al. 2006, 2008; Ahualli et al. 2011). However, the subsequent increase in the nonionic surfactant concentration results in a corresponding increase in the number of $\mathrm{SiO}_{2}$ NPs at the interface (Ravera et al. 2006, 2008). $\mathrm{SiO}_{2} \mathrm{NPs}$ that are bonded to surfactant on their surface can operate as carriers of Tween ${ }^{\circledR} 20$ toward the interface. The decrease in IFT may be attributed to surfactant release from the $\mathrm{SiO}_{2}$ NPs or the direct effect of surfactant-coated $\mathrm{SiO}_{2} \mathrm{NPs}$ on the IFT (Ahualli et al. 2011).

Furthermore, based upon thermodynamic models, the thermodynamically positive occurrence of $\mathrm{SiO}_{2} \mathrm{NPs}$ at the interfaces of oil-aqueous systems causes a decrease in IFT (Paunov et al. 2002). Essentially, the adsorption of $\mathrm{SiO}_{2}$ NPs at interface reduces the energy of the brine-surfactant$\mathrm{SiO}_{2}$ nanofluid-oil system (Paunov et al. 2002). The adsorption of the $\mathrm{SiO}_{2}$ NPs also modifies the entropy of these systems. As the $\mathrm{SiO}_{2}$ NPs are transported to the interface, this movement will generate more space for the aqueous molecules and, consequently, the entropy of the brine-surfactant- $\mathrm{SiO}_{2}$ nanofluid-oil system changes and undergoes an expansion (Dong and Johnson 2003). These phenomena serve as the catalyst for a decrease in the total free energy of the brine-surfactant- $\mathrm{SiO}_{2}$ nanofluid-oil system (Defay and Prigoin 1966), which therefore induces the IFT of this system to decrease.

The increase of the concentration of the nonionic surfactant increases the migration of $\mathrm{SiO}_{2} \mathrm{NPs}$ towards the interface indicating that capillary force phenomenon is the causative factor of this increase in IFT (Dong and Johnson 2003). The location of the $\mathrm{SiO}_{2}$ NPs at an interface causes a lateral manifestation of the capillary forces. Finally, the increased interaction between NPs from the large $\mathrm{SiO}_{2} \mathrm{NP}$ concentrations generates a strong capillary force at the interface that can withstand the distortion at the interface, and thus increase the IFT. Competition between $\mathrm{SiO}_{2} \mathrm{NPs}$ and surfactant for adsorption at the interface of oil-water system has also been reported by Pichot et al. (2012).

\section{Effects of oil properties on interfacial tension at the oil-aqueous interface for brine-surfactant- $\mathrm{SiO}_{2}$ nanofluid-oil systems}

The ability of the $\mathrm{SiO}_{2}$ NPs and surfactant to decrease the IFT is related to the type of crude oil, with different behaviors of IFT between oil and aqueous phase observed for the different oil types. The overall effectiveness of the 
brine-surfactant- $\mathrm{SiO}_{2}$ nanofluids in decreasing the IFT between the oil-aqueous phase in the three crude oil samples was as follows: Prudhoe Bay $>$ Lloydminster $>$ West Texas Intermediate. Based on the physico-chemical characteristics of the three oils examined (Table 1) and the effectiveness of the brine-surfactant- $\mathrm{SiO}_{2}$ nanofluids in decreasing the IFT between the oil-aqueous phase that are reported in our study (Figs. 8, 10, and 12), we hypothesize that the asphaltenes and resins that are the heavy oil components of crude oils are most critical in affecting the IFT behavior between crude oil and brine-surfactant- $\mathrm{SiO}_{2}$ nanofluids. Furthermore, we also elucidate the potential synergistic effects of $\mathrm{NaCl}$ ions from the brine, the asphaltenes and resins, the presence of surfactant, and the $\mathrm{SiO}_{2}$ NPs on IFTs of crude oil and high salinity brine systems. The content in asphaltenes and resins of the crude oils were ranked as follows: Prudhoe Bay (medium oil) $>$ Lloydminster (heavy oil) $>$ West Texas Intermediate (light oil). Therefore, our study demonstrates that the IFT between the oil-aqueous phase of crude oils containing the highest amount of asphaltenes and resins, which are Prudhoe Bay (medium oil) and Lloydminster (heavy oil) were the two most affected by the brine-surfactant- $\mathrm{SiO}_{2}$ nanofluid. The IFT between the oil-aqueous phase of the crude oil with the lowest amount of asphaltenes and resins, however, which was the West Texas Intermediate (light oil), was not affected at all by this method. It can be concluded that both the asphaltenes and resins within these crude oils are crucial for the control of the IFT in crude oilsurfactant-nanofluid systems. The most important active component in crude oil for the control of IFT, however, as determined by Cao et al. (2016) was the acidic fraction that is contained in the resin component of all three crude oils examined. Therefore, we conclude that the $\mathrm{SiO}_{2} \mathrm{NPs}$, the surfactant, and the fractions of asphaltene and resin in crude oil cause the synergistic effect in the oil-surfactant nanofluid interface to decrease the IFT. Although similar synergistic phenomena have been previously reported (Zhang et al. 2014; Lashkarbolooki and Ayatollahi 2016; Lashkarbolooki et al. 2016a, b), further investigations are necessary to elucidate the synergistic mechanisms of these active surfaces at the interfaces between oil-aqueous phases.

\section{Conclusions}

The following results were determined from our analysis of the IFT at the oil-aqueous interface for $5 \mathrm{wt} \%$ brine-surfactant- $\mathrm{SiO}_{2}$ nanofluid-oil systems for three oil types, West Texas Intermediate light crude oil, Prudhoe Bay medium crude oil, and Lloydminster heavy crude oil. Specifically, we observed that:
- The $\mathrm{SiO}_{2}$ nanofluids may either decrease, increase or have no effect whatsoever upon the IFT of brinesurfactant-oil systems.

- The constituents of the oil and aqueous substances do affect the IFT behavior of brine-surfactant-oil systems, with the presence of nanoparticles leading to contrasting IFT trends according to the type of crude oil.

- The IFT increased for the light oil system (0.5 and 2 CMC Tween ${ }^{\circledR} 20$ ) as a function of $\mathrm{SiO}_{2}$ NPs concentration.

- In terms of the IFT trends, a threshold concentration of $\mathrm{SiO}_{2} \mathrm{NPs}$ occurred for the medium $(0.5$ and $2 \mathrm{CMC}$ Tween $\left.{ }^{\circledR} 20\right)$ and heavy $\left(2\right.$ CMC Tween $\left.{ }^{\circledR} 20\right)$ oil systems with concentrations above and below this $\mathrm{SiO}_{2}$ NPs threshold concentration increasing and decreasing the IFT respectively.

- The synergistic/antagonistic effects between crude oil and $\mathrm{SiO}_{2}$ nanofluids occurred in terms of reducing IFT which decreased until the NP concentrations reached a threshold at which point the synergetic effects between nonionic surfactant and $\mathrm{SiO}_{2} \mathrm{NPs}$ were the opposite and resulted in antagonistic effects.

- The adsorption of both $\mathrm{SiO}_{2} \mathrm{NPs}$ and surfactants at an interface caused a synergistic effect to increase the IFT reduction.

- The asphaltenes and resins are critical components of crude oils for controlling IFT of crude oil-surfactantnanofluid systems.

- The level of effectiveness of the brine-surfactant- $\mathrm{SiO}_{2}$ nanofluids in decreasing the IFT between the oilaqueous phase and mimicking the content of asphaltenes and resins in the crude oils for the three tested crude oils were: (1) Prudhoe Bay > (2) Lloydminster > (3) West Texas Intermediate.

- $\mathrm{SiO}_{2}$ nanofluids can decrease IFT and therefore capillary pressure to induce the movement and recovery of oil in original water-wet reservoirs.

- $\mathrm{SiO}_{2}$ nanofluids can increase IFT and, therefore, capillary pressure to increase oil recovery in reservoirs subject to wettability reversal to water-wet conditions.

- Raspberry-like morphology particles were observed in $5 \mathrm{wt} \%$ brine-surfactant- $\mathrm{SiO}_{2}$ nanofluid-oil systems.

- The development of raspberry-like particles material with high surface area, high salt stability, and high capability of interfaces alteration and therefore wettability changes offers a wide range of applications in the fields of applied nanoscience, environmental engineering, and petroleum engineering.

Acknowledgements We wish to convey our appreciation to Clemson University for supporting this work and to Dr. Cindy Lee in the Clemson University Department of Environmental Engineering and Earth Sciences for providing some of the crude oil samples used in 
these experiments. We also wish to acknowledge the technical assistance of Linlin $\mathrm{Mu}$ in the completion of this study. The authors thank Muhammad Mustafa Hussain, Editor-in-Chief of Applied Nanoscience; and the two reviewers for their useful comments.

Open Access This article is distributed under the terms of the Creative Commons Attribution 4.0 International License (http:// creativecommons.org/licenses/by/4.0/), which permits unrestricted use, distribution, and reproduction in any medium, provided you give appropriate credit to the original author(s) and the source, provide a link to the Creative Commons license, and indicate if changes were made.

\section{References}

Ahualli S, Iglesias GR, Wachter W et al (2011) Adsorption of anionic and cationic surfactants on anionic colloids: supercharging and destabilization. Langmuir 27:9182-9192. https://doi.org/10. 1021/la201242d

Amaya J, Rana D, Hornof V (2002) Dynamic interfacial tension behavior of water/oil systems containing in situ-formed surfactants. J Solut Chem 31:139-148. https://doi.org/10.1023/a: 1015201119955

Bear J (1988) Dynamics of fluids in porous media. Dover Publications Inc., New York

Binks BP (2002) Particles as surfactants_-similarities and differences. Curr Opin Colloid Interface Sci 7:21-41. https://doi.org/10.1016/ s1359-0294(02)00008-0

Binks BP, Whitby CP (2005) Nanoparticle silica-stabilised oil-inwater emulsions: improving emulsion stability. Colloids Surfaces A 253:105-115. https://doi.org/10.1016/j.colsurfa.2004.10. 116

Biswal NR, Singh JK (2016) Interfacial behavior of nonionic Tween 20 surfactant at oil-water interfaces in the presence of different types of nanoparticles. Rsc Adv 6:113307-113314. https://doi. org/10.1039/c6ra23093h

Biswal NR, Rangera N, Singh JK (2016) Effect of different surfactants on the interfacial behavior of the n-hexane-water system in the presence of silica nanoparticles. J Phys Chem B 120:7265-7274. https://doi.org/10.1021/acs.jpcb.6b03763

Bouchard D, Zhang W, Powell T, Rattanaudompol US (2012) Aggregation kinetics and transport of single-walled carbon nanotubes at low surfactant concentrations. Environ Sci Technol 46:4458-4465. https://doi.org/10.1021/es204618v

Brian BW, Chen JC (1987) Surface-tension of solid-liquid slurries. AIChe J 33:316-318. https://doi.org/10.1002/aic.690330220

Cao JH, Zhou ZH, Xu ZC et al (2016) Synergism/antagonism between crude oil fractions and novel betaine solutions in reducing interfacial tension. Energy Fuels 30:924-932. https:// doi.org/10.1021/acs.energyfuels.5b02566

Carcouet CCM (2014) Chemistry and morphology of silica nanoparticles. Eindhoven: Technische Universiteit Eindhoven. https:// doi.org/10.6100/IR762547. http://repository.tue.nl/762547. Accessed 26 Oct 2017

Carcouet C, van de Put MWP, Mezari B et al (2014) Nucleation and growth of monodisperse silica nanoparticles. Nano Lett 14:1433-1438. https://doi.org/10.1021/nl404550d

Chen Q, Saltiel C, Manickavasagam S et al (2004) Aggregation behavior of single-walled carbon nanotubes in dilute aqueous suspension. J Colloid Interface Sci 280:91-97. https://doi.org/10. 1016/j.jcis.2004.07.028

Cieslinski JT, Krygier KA (2014) Sessile droplet contact angle of water- $\mathrm{Al}_{2} \mathrm{O}_{3}$, water- $\mathrm{TiO}_{2}$ and water- $\mathrm{Cu}$ nanofluids. Exp Therm
Fluid Sci 59:258-263. https://doi.org/10.1016/j.expthermflusci. 2014.06.004

Defay R, Prigoin I (1966) Surface tension and adsorption. Wiley, New York

Donaldson EC, Chilingarian GV, Yen TF (1989) Enhanced oil recovery, II: processes and operations. Elsevier Science Publishers B.V, Amsterdam

Dong LC, Johnson D (2003) Surface tension of charge-stabilized colloidal suspensions at the water-air interface. Langmuir 19:10205-10209. https://doi.org/10.1021/la035128j

Ehtesabi H, Ahadian MM, Taghikhani V, Ghazanfari MH (2014) Enhanced heavy oil recovery in sandstone cores using $\mathrm{TiO}_{2}$ nanofluids. Energy Fuels 28:423-430. https://doi.org/10.1021/ ef $401338 \mathrm{c}$

Elder KR, Grant M, Provatas N, Kosterlitz JM (2001) Sharp interface limits of phase-field models. Phys Rev E. https://doi.org/10. 1103/PhysRevE.64.021604

Environment Canada (2017a) West Texas Intermediate. http://www. etc-cte.ec.gc.ca/databases/Oilproperties/pdf/WEB_West_Texas_ Intermediate.pdf. Accessed 16 May 2017

Environment Canada (2017b) Prudhoe Bay. http://www.etc-cte.ec.gc. ca/databases/OilProperties/pdf/WEB_Prudhoe_Bay_(1995).pdf. Accessed 16 May 2017

Environment Canada (2017c) Lloydminster. http://www.etc-cte.ec.gc. ca/databases/OilProperties/pdf/WEB_Lloydminster.pdf. Accessed 16 May 2017

Eskandar NG, Simovic S, Prestidge CA (2007) Synergistic effect of silica nanoparticles and charged surfactants in the formation and stability of submicron oil-in-water emulsions. Phys Chem Chem Phys 9:6426-6434. https://doi.org/10.1039/b710256a

Esmaeilzadeh P, Hosseinpour N, Bahramian A et al (2014) Effect of $\mathrm{ZrO}_{2}$ nanoparticles on the interfacial behavior of surfactant solutions at air-water and n-heptane-water interfaces. Fluid Phase Equilib 361:289-295. https://doi.org/10.1016/j.fluid.2013. 11.014

Espinasse B, Hotze EM, Wiesner MR (2007) Transport and retention of colloidal aggregates of C-60 in porous media: effects of organic macromolecules, ionic composition, and preparation method. Environ Sci Technol 41:7396-7402. https://doi.org/10. 1021/es0708767

Fan X, Zheng LF, Cheng J et al (2012) Template synthesis of raspberry-like polystyrene/ $/ \mathrm{SiO}_{2}$ composite microspheres and their application in wettability gradient surfaces. Surf Coat Technol 213:90-97. https://doi.org/10.1016/j.surfcoat.2012.10. 025

Fang J, Shan XQ, Wen B, Huang RX (2013) Mobility of TX100 suspended multiwalled carbon nanotubes (MWCNTs) and the facilitated transport of phenanthrene in real soil columns. Geoderma 207:1-7. https://doi.org/10.1016/j.geoderma.2013.04. 035

Fletcher A, Davis J (2010) How EOR can be transformed by nanotechnology. In: Soc. Pet. Eng. Symp. Improv. Oil Recover. SPE-129531-MS

$\mathrm{Fu} \mathrm{KF}$, Sun YP (2003) Dispersion and solubilization of carbon nanotubes. J Nanosci Nanotechnol 3:351-364. https://doi.org/10. 1166/jnn.2003.225

Ganguly S, Chakraborty S (2011) Sedimentation of nanoparticles in nanoscale colloidal suspensions. Phys Lett A 375:2394-2399. https://doi.org/10.1016/j.physleta.2011.04.018

Ghadimi A, Metselaar IH (2013) The influence of surfactant and ultrasonic processing on improvement of stability, thermal conductivity and viscosity of titania nanofluid. Exp Therm Fluid Sci 51:1-9. https://doi.org/10.1016/j.expthermflusci.2013.06.001

Ghezzi F, Earnshaw JC, Finnis M, McCluney M (2001) Pattern formation in colloidal monolayers at the air-water interface.

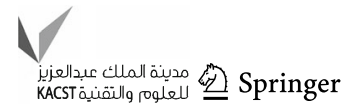


J Colloid Interface Sci 238:433-446. https://doi.org/10.1006/jcis. 2001.7495

Godinez IG, Darnault CJG (2011) Aggregation and transport of nano$\mathrm{TiO}_{2}$ in saturated porous media: effects of $\mathrm{pH}$, surfactants and flow velocity. Water Res 45:839-851. https://doi.org/10.1016/j. watres.2010.09.013

Godinez IG, Darnault CJG, Khodadoust AP, Bogdan D (2013) Deposition and release kinetics of nano- $\mathrm{TiO}_{2}$ in saturated porous media: effects of solution ionic strength and surfactants. Environ Pollut 174:106-113. https://doi.org/10.1016/j.envpol.2012.11.002

Gonzenbach UT, Studart AR, Tervoort E, Gauckler LJ (2006) Stabilization of foams with inorganic colloidal particles. Langmuir 22:10983-10988. https://doi.org/10.1021/la061825a

Griffith N, Ahmad Y, Daigle H, Huh C (2016) Nanoparticle-stabilized natural gas liquid-in-water emulsions for residual oil recovery. In: Soc. Pet. Eng. Symp. Improv. Oil Recover. SPE-179640-MS

Hendraningrat L, Torsæter O (2014) Effects of the initial rock wettability on silica-based nanofluid-enhanced oil recovery processes at reservoir temperatures. Energy Fuels 28:6228-6241. https://doi.org/10.1021/ef5014049

Hendraningrat L, Torsæter O (2015a) A stabilizer that enhances the oil recovery process using silica-based nanofluids. Transp Porous Media 108:679-696. https://doi.org/10.1007/s11242-015-0495-8

Hendraningrat L, Torsæter O (2015b) Metal oxide-based nanoparticles: revealing their potential to enhance oil recovery in different wettability systems. Appl Nanosci 5:181-199. https://doi.org/10. 1007/s13204-014-0305-6

Hendraningrat L, Li SD, Torsæter O (2013) A coreflood investigation of nanofluid enhanced oil recovery. J Pet Sci Eng 111:128-138. https://doi.org/10.1016/j.petrol.2013.07.003

Hu ZL, Azmi SM, Raza G et al (2016a) Nanoparticle-assisted waterflooding in Berea sandstones. Energy Fuels 30:2791-2804. https://doi.org/10.1021/acs.energyfuels.6b00051

$\mathrm{Hu}$ C, West KR, Scherman OA (2016b) Hollow mesoporous raspberry-like colloids with removable caps as photoresponsive nanocontainers. Nanoscale 8:7840-7844. https://doi.org/10. 1039/c6nr01016d

Huibers BMJ, Pales AR, Bai L et al (2017) Wettability alteration of sandstones by silica nanoparticle dispersions in light and heavy crude oil. J Nanopart Res 19:323. https://doi.org/10.1007/ s11051-017-4011-7

Hyung H, Fortner JD, Hughes JB, Kim JH (2007) Natural organic matter stabilizes carbon nanotubes in the aqueous phase. Environ Sci Technol 41:179-184. https://doi.org/10.1021/es061817g

Jadhunandan PP, Morrow NR (1995) Effect of wettability on waterflood recovery for crude-oil brine rock systems. Spe Reserv Eng 10:40-46. https://doi.org/10.2118/22597-pa

Jaisi DP, Saleh NB, Blake RE, Elimelech M (2008) Transport of single-walled carbon nanotubes in porous media: filtration mechanisms and reversibility. Environ Sci Technol 42:8317-8323. https://doi.org/10.1021/es801641v

Jiang LQ, Gao L, Sun J (2003) Production of aqueous colloidal dispersions of carbon nanotubes. J Colloid Interface Sci 260:89-94. https://doi.org/10.1016/s0021-9797(02)00176-5

Joonaki E, Ghanaatian S (2014) The application of nanofluids for enhanced oil recovery: effects on interfacial tension and coreflooding Process. Pet Sci Technol 32:2599-2607. https:// doi.org/10.1080/10916466.2013.855228

Karimi A, Fakhroueian Z, Bahramian A et al (2012) Wettability alteration in carbonates using zirconium oxide nanofluids: EOR implications. Energy Fuels 26:1028-1036. https://doi.org/10. 1021/ef201475u

Kasel D, Bradford SA, Simunek J et al (2013) Transport and retention of multi-walled carbon nanotubes in saturated porous media: effects of input concentration and grain size. Water Res 47:933-944. https://doi.org/10.1016/j.watres.2012.11.019
Kresge CT, Leonowicz ME, Roth WJ et al (1992) Ordered mesoporous molecular-sieves synthesized by a liquid-crystal template mechanism. Nature 359:710-712. https://doi.org/10. 1038/359710a0

Lan Q, Yang F, Zhang SY et al (2007) Synergistic effect of silica nanoparticle and cetyltrimethyl ammonium bromide on the stabilization of $\mathrm{O} / \mathrm{W}$ emulsions. Colloids Surfaces A 302:126-135. https://doi.org/10.1016/j.colsurfa.2007.02.010

Lanphere JD, Rogers B, Luth C et al (2014) Stability and transport of graphene oxide nanoparticles in groundwater and surface water. Environ Eng Sci 31:350-359. https://doi.org/10.1089/ees.2013. 0392

Lashkarbolooki M, Ayatollahi S (2016) Effect of asphaltene and resin on interfacial tension of acidic crude oil/sulfate aqueous solution: experimental study. Fluid Phase Equilib 414:149-155. https://doi.org/10.1016/j.fluid.2016.01.032

Lashkarbolooki M, Riazi M, Ayatollahi S (2016a) Investigation of effects of salinity, temperature, pressure, and crude oil type on the dynamic interfacial tensions. Chem Eng Res Des 115:53-65. https://doi.org/10.1016/j.cherd.2016.09.020

Lashkarbolooki M, Riazi M, Ayatollahi S, Hezave AZ (2016b) Synergy effects of ions, resin, and asphaltene on interfacial tension of acidic crude oil and low-high salinity brines. Fuel 165:75-85. https://doi.org/10.1016/j.fuel.2015.10.030

Lecoanet HF, Wiesner MR (2004) Velocity effects on fullerene and oxide nanoparticle deposition in porous media. Environ Sci Technol 38:4377-4382. https://doi.org/10.1021/es035354f

Lecoanet HF, Bottero JY, Wiesner MR (2004) Laboratory assessment of the mobility of nanomaterials in porous media. Environ Sci Technol 38:5164-5169. https://doi.org/10.1021/es0352303

Lin DH, Li TT, Yang K, Wu FC (2012) The relationship between humic acid (HA) adsorption on and stabilizing multiwalled carbon nanotubes (MWNTs) in water: effects of HA, MWNT and solution properties. J Hazard Mater 241:404-410. https://doi. org/10.1016/j.jhazmat.2012.09.060

Liu XY, O'Carroll DM, Petersen EJ et al (2009) Mobility of multiwalled carbon nanotubes in porous media. Environ Sci Technol 43:8153-8158. https://doi.org/10.1021/es901340d

Ma H, Luo M, Dai LL (2008) Influences of surfactant and nanoparticle assembly on effective interfacial tensions. Phys Chem Chem Phys 10:2207. https://doi.org/10.1039/b718427c

Matarredona O, Rhoads H, Li ZR et al (2003) Dispersion of singlewalled carbon nanotubes in aqueous solutions of the anionic surfactant NaDDBS. J Phys Chem B 107:13357-13367. https:// doi.org/10.1021/jp0365099

Mattison NT, O'Carroll DM, Rowe RK, Petersen EJ (2011) Impact of porous media grain size on the transport of multi-walled carbon nanotubes. Environ Sci Technol 45:9765-9775. https://doi.org/ $10.1021 /$ es2017076

Meeusen R (2017) The synthesis of raspberry-like particles utilizing a heterocoagulation technique. Hogeschool Utrecht University of Applied Sciences Utrecht. https://www.hbo-kennisbank.nl/en/ record/sharekit_hu/oai:surfsharekit.nl:a9a855b6-b1ad-42348337-4364bd6a105f. Accessed 26 Oct 2017

Mekonen A, Sharma P, Fagerlund F (2014) Transport and mobilization of multiwall carbon nanotubes in quartz sand under varying saturation. Environ Earth Sci 71:3751-3760. https://doi.org/10. 1007/s12665-013-2769-1

Moghadam TF, Azizian S (2014a) Effect of ZnO nanoparticle and hexadecyltrimethylammonium bromide on the dynamic and equilibrium oil-water interfacial tension. J Phys Chem B 118:1527-1534. https://doi.org/10.1021/jp4106986

Moghadam TF, Azizian S (2014b) Synergistic effect of $\mathrm{ZnO}$ nanoparticles and triblock copolymer surfactant on the dynamic and equilibrium oil-water interfacial tension. Soft Matter 10:6192-6197. https://doi.org/10.1039/c4sm01027b 
Moghadam TF, Azizian S (2014c) Effect of ZnO nanoparticles on the interfacial behavior of anionic surfactant at liquid/liquid interfaces. Colloids Surfaces A 457:333-339. https://doi.org/10.1016/ j.colsurfa.2014.06.009

Moghadam TF, Azizian S, Wettig S (2015) Synergistic behaviour of $\mathrm{ZnO}$ nanoparticles and gemini surfactants on the dynamic and equilibrium oil/water interfacial tension. Phys Chem Chem Phys 17:7122-7129. https://doi.org/10.1039/c5cp00510h

Mohan K, Gupta R, Mohanty KK (2011) Wettability altering secondary oil recovery in carbonate rocks. Energy Fuels 25:3966-3973. https://doi.org/10.1021/ef200449y

O'Carroll DM, Liu X, Mattison NT, Petersen EJ (2013) Impact of diameter on carbon nanotube transport in sand. J Colloid Interface Sci 390:96-104. https://doi.org/10.1016/j.jcis.2012.09. 034

Pales AR, Kinsey EN, Li C et al (2017) Rheological properties of silica nanoparticles in brine and brine-surfactant systems. J Nanofluids 6:795-803

Park S, Lee ES, Sulaiman WRW (2015) Adsorption behaviors of surfactants for chemical flooding in enhanced oil recovery. J Ind Eng Chem 21:1239-1245. https://doi.org/10.1016/j.jiec.2014.05. 040

Paunov VN, Binks BP, Ashby NP (2002) Adsorption of charged colloid particles to charged liquid surfaces. Langmuir 18:6946-6955. https://doi.org/10.1021/la0203584

Pichot R, Spyropoulos F, Norton IT (2012) Competitive adsorption of surfactants and hydrophilic silica particles at the oil-water interface: interfacial tension and contact angle studies. J Colloid Interface Sci 377:396-405. https://doi.org/10.1016/j.jcis.2012. 01.065

Pu WF, Zhao S, Lu XB et al (2016) The effect of oil properties on oil recovery in dilute surfactant flooding. Pet Sci Technol 34:759-764. https://doi.org/10.1080/10916466.2016.1163398

Ranatunga R, Nguyen CT, Wilson BA et al (2011) Molecular dynamics study of nanoparticles and non-ionic surfactant at an oil-water interface. Soft Matter 7:6942-6952. https://doi.org/10. 1039/c1sm05145h

Ravari RR, Strand S, Austad T (2011) Combined surfactant-enhanced gravity drainage (SEGD) of oil and the wettability alteration in carbonates: the effect of rock permeability and interfacial tension (IFT). Energy Fuels 25:2083-2088. https://doi.org/10.1021/ ef $200085 t$

Ravera F, Santini E, Loglio G et al (2006) Effect of nanoparticles on the interfacial properties of liquid/liquid and liquid/air surface layers. J Phys Chem B 110:19543-19551. https://doi.org/10. 1021/jp0636468

Ravera F, Ferrari M, Liggieri L et al (2008) Liquid-liquid interfacial properties of mixed nanoparticle-surfactant systems. Colloids Surfaces A 323:99-108. https://doi.org/10.1016/j.colsurfa.2007. 10.017

Roosz N, Euvard M, Lakard B et al (2017) Synthesis and characterization of polyaniline-silica composites: raspberry vs coreshell structures. Where do we stand? J Colloid Interface Sci 502:184-192. https://doi.org/10.1016/j.jcis.2017.04.092

Roustaei A, Bagherzadeh H (2013) An evaluation of modified silica nanoparticles' efficiency in enhancing oil recovery of light and intermediate oil reservoirs. Egypt J Pet 22:427-433

Roustaei A, Bagherzadeh H (2015) Experimental investigation of $\mathrm{SiO}_{2}$ nanoparticles on enhanced oil recovery of carbonate reservoirs. J Pet Explor Prod Technol 5:27-33. https://doi.org/ 10.1007/s13202-014-0120-3

Samanta A, Ojha K, Mandal A (2011) The Characterization of natural surfactant and polymer and their Use in enhanced recovery of oil. Pet Sci Technol 29:765-777. https://doi.org/10.1080/ 10916460903485819
Schwartz H, Harel Y, Efrima S (2001) Surface behavior and buckling of silver interfacial colloid films. Langmuir 17:3884-3892. https://doi.org/10.1021/la0100690

Sharma T, Iglauer S, Sangwai JS (2016) Silica nanofluids in an oilfield polymer polyacrylamide: interfacial properties, wettability alteration, and applications for chemical enhanced oil recovery. Ind Eng Chem Res 55:12387-12397. https://doi.org/ 10.1021/acs.iecr.6b03299

Somasundaran P, Zhang L (2006) Adsorption of surfactants on minerals for wettability control in improved oil recovery processes. J Pet Sci Eng 52:198-212. https://doi.org/10.1016/j. petrol.2006.03.022

Standnes DC, Austad T (2000a) Wettability alteration in chalk 1. Preparation of core material and oil properties. J Pet Sci Eng 28:111-121. https://doi.org/10.1016/s0920-4105(00)00083-8

Standnes DC, Austad T (2000b) Wettability alteration in chalk 2. Mechanism for wettability alteration from oil-wet to water-wet using surfactants. J Pet Sci Eng 28:123-143. https://doi.org/10. 1016/s0920-4105(00)00084-x

Stauch C, Spath S, Ballweg T et al (2017) Nanostructured microraspberries from superparamagnetic iron oxide nanoparticles: studying agglomeration degree and redispersibility of nanoparticulate powders via magnetisation measurements. J Colloid Interface Sci 505:605-614. https://doi.org/10.1016/j.jcis.2017.06.047

Strand S, Standnes DC, Austad T (2003) Spontaneous imbibition of aqueous surfactant solutions into neutral to oil-wet carbonate cores: effects of brine salinity and composition. Energy Fuels 17:1133-1144. https://doi.org/10.1021/ef030051s

Strand S, Austad T, Puntervold T et al (2008) "Smart water" for oil recovery from fractured limestone: a preliminary study. Energy Fuels 22:3126-3133. https://doi.org/10.1021/ef800062n

Suleimanov BA, Ismailov FS, Veliyev EF (2011) Nanofluid for enhanced oil recovery. J Pet Sci Eng 78:431-437. https://doi.org/ 10.1016/j.petrol.2011.06.014

Tabrizy VA, Hamouda AA, Denoyel R (2011) Influence of magnesium and sulfate ions on wettability alteration of calcite, quartz, and kaolinite: surface energy analysis. Energy Fuels 25:1667-1680. https://doi.org/10.1021/ef200039m

Uyusur B, Darnault CJG, Snee PT et al (2010) Coupled effects of solution chemistry and hydrodynamics on the mobility and transport of quantum dot nanomaterials in the vadose zone. J Contam Hydrol 118:184-198. https://doi.org/10.1016/j. jconhyd.2010.09.013

Uzelac B, Valmacco V, Trefalt G (2017) Interactions between silica particles in the presence of multivalent coions. Soft Matter 13:5741-5748. https://doi.org/10.1039/c7sm01168g

Wang H, Zhou W, Ho DL et al (2004) Dispersing single-walled carbon nanotubes with surfactants: a small angle neutron scattering study. Nano Lett 4:1789-1793. https://doi.org/10. $1021 / \mathrm{nl} 048969 \mathrm{z}$

Wang YG, Li YS, Fortner JD et al (2008a) Transport and retention of nanoscale C-60 aggregates in water-saturated porous media. Environ Sci Technol 42:3588-3594. https://doi.org/10.1021/ es $800128 \mathrm{~m}$

Wang YG, Li YS, Pennell KD (2008b) Influence of electrolyte species and concentration on the aggregation and transport of fullerene nanoparticles in quartz sands. Environ Toxicol Chem 27:1860-1867. https://doi.org/10.1897/08-039.1

Wang YF, Xu HM, Yu WZ et al (2011) Surfactant induced reservoir wettability alteration: recent theoretical and experimental advances in enhanced oil recovery. Pet Sci 8:463-476. https:// doi.org/10.1007/s12182-011-0164-7

Wu YF, Shuler PJ, Blanco M et al (2008) An experimental study of wetting behavior and surfactant EOR in carbonates with model compounds. Spe J 13:26-34 
Yu L, Evje S, Kleppe H, et al (2008) Analysis of the wettability alteration process during seawater imbibition into preferentially oil-wet chalk cores. In: Soc. Pet. Eng. Symp. Improv. Oil Recover. SPE-113304-MS

Yu H, Yoon KY, Neilson BM et al (2014) Transport and retention of aqueous dispersions of superparamagnetic nanoparticles in sandstone. J Pet Sci Eng 116:115-123. https://doi.org/10.1016/ j.petrol.2013.08.053

Yu MG, Wang Q, Zhang M et al (2017) Facile fabrication of raspberry-like composite microspheres for the construction of superhydrophobic films and applications in highly efficient oilwater separation. Rsc Adv 7:39471-39479. https://doi.org/10. 1039/c7ra07250c

Yuan CD, Pu WF, Wang XC et al (2015) Effects of interfacial tension, emulsification, and surfactant concentration on oil recovery in surfactant flooding process for high temperature and high salinity reservoirs. Energy Fuels 29:6165-6176. https:// doi.org/10.1021/acs.energyfuels.5b01393

Zanini M, Hsu CP, Magrini T et al (2017) Fabrication of rough colloids by heteroaggregation. Colloids Surfaces A 532:116-124. https://doi.org/10.1016/j.colsurfa.2017.05.084
Zargartalebi M, Barati N, Kharrat R (2014) Influences of hydrophilic and hydrophobic silica nanoparticles on anionic surfactant properties: interfacial and adsorption behaviors. J Pet Sci Eng 119:36-43. https://doi.org/10.1016/j.petrol.2014.04.010

Zargartalebi M, Kharrat R, Barati N (2015) Enhancement of surfactant flooding performance by the use of silica nanoparticles. Fuel 143:21-27. https://doi.org/10.1016/j.fuel.2014.11.040

Zhang H, Nikolov A, Wasan D (2014) Enhanced oil recovery (EOR) using nanoparticle dispersions: underlying mechanism and imbibition experiments. Energy Fuels 28:3002-3009. https:// doi.org/10.1021/ef500272r

Zhao CX, Middelberg APJ (2013) Microfluidic synthesis of monodisperse hierarchical silica particles with raspberry-like morphology. Rsc Adv 3:21227-21230. https://doi.org/10.1039/ c3ra42362j

\section{Publisher's Note}

Springer Nature remains neutral with regard to jurisdictional claims in published maps and institutional affiliations. 